\title{
Evaluation of high-resolution forecasts with the non-hydrostatic numerical weather prediction model Lokalmodell for urban air pollution episodes in Helsinki, Oslo and Valencia
}

\author{
B. Fay ${ }^{1}$ and L. Neunhäuserer ${ }^{1, *}$ \\ ${ }^{1}$ German Weather Service DWD, Offenbach, Germany \\ *now at: IVU Umwelt GmbH, Freiburg, Germany
}

Received: 30 June 2005 - Published in Atmos. Chem. Phys. Discuss.: 8 September 2005

Revised: 7 February 2006 - Accepted: 5 April 2006 - Published: 20 June 2006

\begin{abstract}
The operational numerical weather prediction model Lokalmodell LM with $7 \mathrm{~km}$ horizontal resolution was evaluated for forecasting meteorological conditions during observed urban air pollution episodes. The resolution was increased to experimental $2.8 \mathrm{~km}$ and $1.1 \mathrm{~km}$ resolution by one-way interactive nesting without introducing urbanisation of physiographic parameters or parameterisations. The episodes examined are two severe winter inversion-induced episodes in Helsinki in December 1995 and Oslo in January 2003, three suspended dust episodes in spring and autumn in Helsinki and Oslo, and a late-summer photochemical episode in the Valencia area. The evaluation was basically performed against observations and radiosoundings and focused on the LM skill at forecasting the key meteorological parameters characteristic for the specific episodes. These included temperature inversions, atmospheric stability and low wind speeds for the Scandinavian episodes and the development of mesoscale recirculations in the Valencia area. LM forecasts often improved due to higher model resolution especially in mountainous areas like Oslo and Valencia where features depending on topography like temperature, wind fields and mesoscale valley circulations were better described. At coastal stations especially in Helsinki, forecast gains were due to the improved physiographic parameters (land fraction, soil type, or roughness length). The Helsinki and Oslo winter inversions with extreme nocturnal inversion strengths of $18^{\circ} \mathrm{C}$ were not sufficiently predicted with all LM resolutions. In Helsinki, overprediction of surface temperatures and low-level wind speeds basically led to underpredicted inversion strength. In the Oslo episode, the situation was more complex involving erroneous temperature advection and mountain-induced effects for the higher resolutions. Possible explanations include the influence of the LM treatment of snow cover, sea ice and stability-dependence of
\end{abstract}

Correspondence to: B. Fay

(barbara.fay@dwd.de) transfer and diffusion coefficients. The LM simulations distinctly improved for winter daytime and nocturnal spring and autumn inversions and showed good skill at forecasting further episode-relevant meteorological parameters. The evaluation of the photochemical Valencia episode concentrated on the dominating mesoscale circulation patterns and showed that the LM succeeds well in describing all the qualitative features observed in the region. LM performance in forecasting the examined episodes thus depends on the key episode characteristics and also the season of the year with a need to improve model performance in very stable inversion conditions not only for urban simulations.

\section{Introduction}

In atmospheric dispersion modelling, local (below $1 \mathrm{~km}$ ) meteorological input data are traditionally requested for longerterm meteorological and air quality assessment modelling and provided with diagnostic models. They are based on and closely reproduce local measurements or diagnostic meteorological data, are mass conserving and computationally fast but simulate stationary conditions and may suffer from simplified parameterisations and scarce or non-representative observations. Air pollution abatement legislation for the protection of world-wide increasing city populations has recently increased the demand for urban meteorological and air pollution forecasting, often in the framework of urban information systems. Numerical weather prediction (NWP) models have also considerably advanced in forecasting skill at horizontal resolutions below $10 \mathrm{~km}$ due to growing computer power, scale-adapted non-hydrostatic equations and physical parameterisations, and grid nesting techniques (Mass et al., 2002). Thus, the historical differences in modelling approaches and applications between regional scale weather forecasting and local scale and obstacle-resolving

Published by Copernicus GmbH on behalf of the European Geosciences Union. 
micro-scale dispersion and air quality simulations will increasingly be bridged (Baklanov et al., 2002).

The benefits of increasing horizontal resolution in NPW models down to the non-hydrostatic or even the neighbourhood scale (about $1 \mathrm{~km}$ ) are reviewed in Mass et al. (2002) for rural mesoscale meteorological model applications, mainly in the U.S. and for the Penn State/NCAR Mesoscale Model version 5 (MM5, Dudhia, 1993). They show that an increase of resolution inside the non-hydrostatic scale has only a limited impact on traditional objective verification scores but increases the realism of mesoscale meteorological structures like orographic winds, circulations etc. Generally, before 2002 only a few investigations consider urban areas. Early applications for urban regions are presented for the Mesoscale Model MEMO, e.g. for Athens (Moussiopoulos, 1995), Barcelona (Toll and Baldasano, 2002) or Zagreb (Klaic and Nitis, 2001). Berge et al. (2002) show an evaluation for Oslo with the nested HIRLAM-MM5 system, Kotroni and Lagouvardos (2004) for Athens with nested MM5 simulations. These investigations confirm benefits of increased grid resolution down to about $1 \mathrm{~km}$ for urban simulations, but also show that further improvements and urbanisation steps are inevitable.

NWP and mesoscale models traditionally lack specifically urban surface and boundary layer characteristics which were investigated e.g. in the COST action 715 (Piringer and Joffre, 2005; Fisher et al., 2006). Various approaches of urbanising mesoscale models reaching from simple to sophisticated were implemented and tested in several models in the last years including e.g. MM5 (Dupont et al., 2004). In the European FP5 project FUMAPEX (Integrated Systems for Forecasting Urban Meteorology, Air Pollution and Population Exposure, 2002-2005, http://fumapex.dmi.dk; Baklanov, 2005), experimental versions of e.g. the Lokalmodell, the SWISS Lokalmodell version aLMo and the Danish DMI-HIRLAM model were urbanised to various degrees (Baklanov, 2005; Baklanov et al., 2005a, b; Neunhäuserer and Fay, 2005, 2006). At the same time, these more or less urbanised models are being prepared for and employed in Urban Air Quality Information and Forecasting Systems (UAQIFSs), e.g. MM5 for Oslo, Norway (Berge et al., 2002) and Sydney-Melbourne, Australia (Cope et al., 2004). Recently enforced European Union air quality regulations increase the need for predictions of local pollutant concentration, and UAQ forecasting is investigated or operational in many large European cities also using an increasing number of nested high-resolution NWP models. Some of these systems were also advanced in the FUMAPEX project (Baklanov, 2005).

Nevertheless, the necessary prerequisite and first step for all these model urbanisation measures is the refinement of the current operational NWP model resolutions (mostly $5 \mathrm{~km}$ and above) to the neighbourhood scale of about $1 \mathrm{~km}$, partly by nesting techniques, in order to sufficiently resolve the city areas. These models were also tested with original and in- creased resolution, but all physical parameterisations remaining unaltered, for forecasting urban episode conditions and part of a model inter-comparison in FUMAPEX (Fay et al., 2004, 2005). Although the current non-urbanised NWP models are not strictly "valid" for urban applications, the results, nevertheless, highlight capabilities, quantify deficiencies and the scope of the needed improvements especially in parameterisations, and may serve as a reference for the results of the urbanised models.

The non-hydrostatic NWP model Lokalmodell (LM) was one of the operational NWP models tested for its performance in forecasting meteorological conditions during some characteristic European air pollution episodes. In the late 1990s, the model was developed at the German Weather Service (DWD) as a fast operational NWP model with improved time-optimised numerics and efficient software-engineering in comparison to the similar, but older models MM5 and MC2 (Mesoscale Compressible Community Model, Bergeron et al., 1994). It also preserves continuity in parameterisation schemes with the former DWD NWP models. Seven European national or regional weather services are now participating in the modelling consortium COSMO for the operational development, application and validation of the LM. The DWD is also Lead Centre for non-hydrostatic modelling in the network of 20 national European weather services (EUMETNET). A new LM short-term version with $2.3 \mathrm{~km}$ horizontal resolution is under development for operations in 2006, especially for improved precipitation forecasting. The presented simulations with up to $1.1 \mathrm{~km}$ horizontal resolution, however, are the first application and evaluation of the LM for forecasting meteorological (episode) conditions in the urban environment in the COSMO and NWP communities.

In Sect. 2, the LM model set-up and the meteorological conditions of the air pollution episodes in Helsinki, Oslo and Valencia are described. The simulation results, their evaluation and interpretation are presented in Sect. 3 while Sect. 4 concludes the discussion and gives a preview of already achieved and future developments in the urbanisation of LM.

\section{Description of the LM set-up and the pollution episodes}

\subsection{The operational LM}

The non-hydrostatic Lokalmodell (LM) was developed at the DWD as a flexible tool to be used for operational NWP on the meso- $\beta$ and meso- $\gamma$ scale as well as for the evaluation of local climate and various scientific applications on a wide range of spatial scales (in a special version down to grid spacings of about $100 \mathrm{~m}$ ). It is operational at the DWD with a horizontal resolution of $7 \mathrm{~km}$ and 35 layers for Central and Western Europe since the end of 1999. A detailed 
(a)

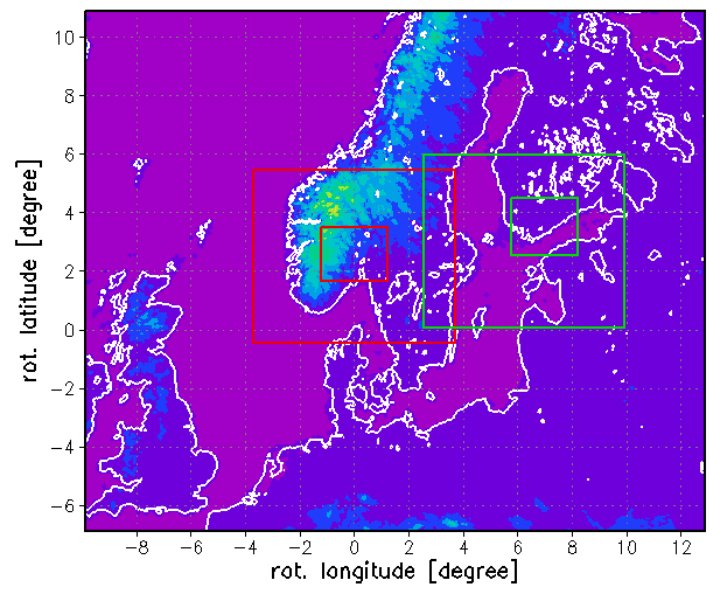

(b)

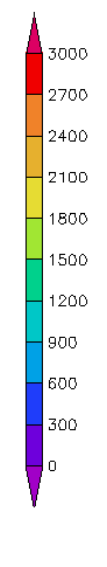

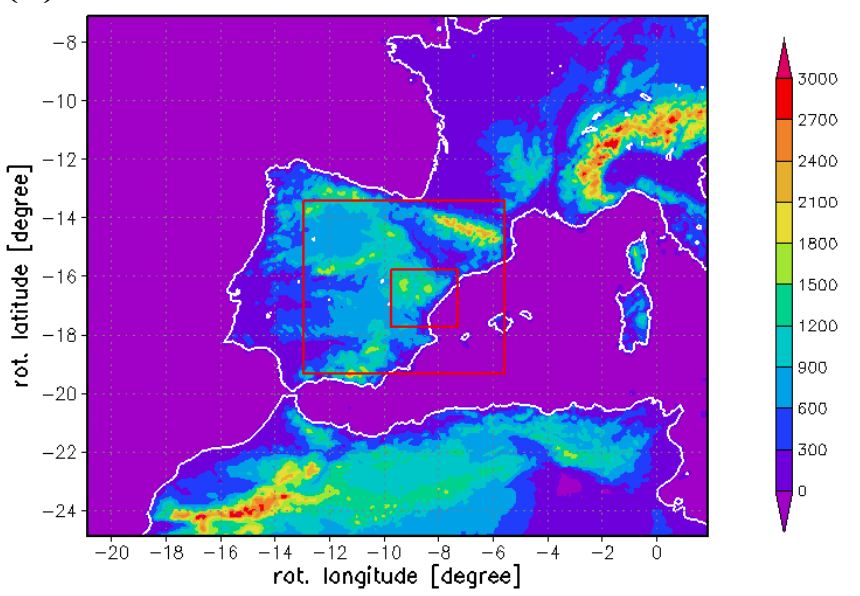

Fig. 1. LM model domains for $7 \mathrm{~km}, 2.8 \mathrm{~km}$ and $1.1 \mathrm{~km}$ resolution. (a) Helsinki and Oslo. (b) Valencia.

description of LM model design and physics is given in Steppeler et al. (2003) and in the documentations provided at the COSMO web site (http://www.cosmo-model.org). The LM version LM 3.5 operational at the time of the simulations was used.

The LM is nested by one-way interactive nesting into the DWD's global model GME with approximately $60 \mathrm{~km}$ horizontal resolution/31 vertical layers and a 2-layer soil model (Majewski et al., 2002, version gmtri_1.25) at the time of the experiments (while later $40 \mathrm{~km} / 40$ layers, a multi-layer soil model and ice phase cloud microphysics were included). The LM is operationally initialised in a four-dimensional data assimilation cycle based on a nudging analysis scheme. Lateral boundary values are provided from GME forecasts. The operational one-way nesting procedure is applied with timedependent relaxation boundary conditions similar to Davies (1976). Using a relaxation boundary zone depth of 8 LM grid points effectively reduces numerical noise created by boundary inhomogeneity. The interpolation of initial and lateral boundary data from GME to LM is performed with a modeladapted interpolation scheme.

\subsection{The LM set-up and nesting for the episode simulations}

The target city simulations in FUMAPEX are designed to follow the operational procedures of the participating weather services as closely as possible. As the target cities Helsinki and Valencia are located outside the operational LM area, the LM domain had to be shifted to Scandinavia and the Iberian Peninsula, respectively. The LM $7 \mathrm{~km}$ nest area covers a large region of $365 \times 285$ grid points $\left(2550 \times 1990 \mathrm{~km}^{2}\right)$ in order to allow development of mesoscale structures in LM independent of GME, especially on the windward side of the target cities. The Scandinavian area also served as outer nest for the Oslo simulations. For each target city, two further one-way self-nested LM domains were inserted as shown in Fig. 1. In contrast to other mesoscale models like MM5 and RAMS, the LM allows nesting with any nesting factor, thus a factor of 2.5 was chosen in order to subdue numerical noise. For the experimental $2.8 \mathrm{~km}$ and $1.1 \mathrm{~km}$ LM nest simulations, no data assimilation and initialisation was performed, but interpolated initial conditions and boundary relaxation were applied. The LM seems quite robust towards initial imbalances, at least from the experience with the operational version. The initial and boundary values were interpolated from the outer to the inner LM nests with an LM-adapted interpolation tool. The medium nest for each target city covered $297 \times 237$ grid points $\left(830 \times 660 \mathrm{~km}^{2}\right)$ with $2.8 \mathrm{~km}$ horizontal resolution. The number of vertical layers was also increased from 35 to 45, especially in the lower boundary layer, with the centre of the lowest model layer moving from about $33 \mathrm{~m}$ to $20 \mathrm{~m}$, and now 13 layers compared to the operational 8 layers in the lowest $1000 \mathrm{~m}$.

The third, inner city nest still encompasses $247 \times 197$ grid points $\left(270 \times 200 \mathrm{~km}^{2}\right)$ with $1.1 \mathrm{~km}$ horizontal resolution and 45 layers. The chosen nests are comparatively large as the forecast length in all resolutions is $48 \mathrm{~h}$ in order to satisfy the requirements of the urban air quality community to take pollution abatement action a day in advance. Special care was taken to avoid placing any nest boundaries on high mountains like the Pyrenees and the Norwegian mountains north of Oslo in order to avoid creating numerical noise or model instability.

Three of the six episodes considered are dated before Dec 1999 when GME analyses are not readily available. A GME cold start was performed using one ECMWF ERA-40 analysis per episode and running the GME for 8 days before starting the episode simulations in order to extinguish ECMWF model influence on the GME as far as possible. The remaining episodes were re-run from one archived GME analysis 
while the lateral boundary values during the forecast were again derived from the corresponding GME forecasts, not from analyses to keep in line with the quasi-operational forecast mode of the experiment.

A new set of physiographic parameters was derived for all grid points of each of the $8 \mathrm{LM}$ domains using the same procedure and database as for the operational LM.

\subsection{Meteorological description of target city episodes}

The project target cities and episodes were chosen from the cities active or interested in air pollution abatement strategies. They represent a variety of European climate regions, seasons and topographic conditions which determine the relative importance of meteorological and other factors causing the episodes (Valkama and Kukkonen, 2004). Explicitly long-range transport episodes were excluded from this study in order to focus on local and mesoscale meteorological phenomena in the high-resolution simulations. The cities involved include Helsinki as a Northern European city with almost flat topography situated on a broken coastline. Oslo is located on an inland fjord enclosed on three sides by hills forming a basin. The Valencia/Castellón area is a conurbation on the flat, open Iberian coast neighbouring high mountains up to $2000 \mathrm{~m}$ and with long, deep valleys reaching inland.

The episodes represent typical regional variants. The Helsinki episodes are winter inversion-induced and spring dust episodes involving particles (and nitrogen dioxide) with possible suspension of particles after thaw and include an extreme radiation-induced inversion case for 1995 (Kukkonen et al., 2005). The Oslo episodes are also typical winter inversion and particle suspension episodes (involving nitrogen dioxide) where inversion conditions are enhanced by topographical mountain basin effects (Valkama and Kukkonen, 2004). The characteristic episode in the Iberian coastal mountain region is a photochemical episode including ozone and particles in spring and summer and depends on complex mesoscale recirculation of pollutants and longer recharging periods (Millán et al., 2002). All episodes can last for one week or more but for the simulations only forecasts covering the most characteristic 3 days (in winter, 5 in summer) were chosen. The episode characteristics following the classification in Kukkonen et al. (2005) are described in Table 1. Additional episode information is provided in the individual target city chapters.

\section{Results and evaluation}

\subsection{Model evaluation}

The evaluation focuses on the meteorological parameters relevant in the urban environment and performed against measurements at urban observation stations whenever possible. The different climate regions, seasons of the year and episode types require a different focus of evaluation for each target city (Sokhi et al., 2002; Piringer and Kukkonen, 2002; Kukkonen et al., 2005). The LM performance in forecasting the main meteorological factors characterising the episodes is evaluated using horizontal fields and vertical profiles for single parameters at station locations every 6 forecast hours, $48 \mathrm{~h}$ forecast time series of single parameters and of vertical profiles at station locations and vertical cross-sections.

The model forecasting skill at fixed observation stations also depends on the quality and representativeness of these observations. The observations of the mainly WMO SYNOP stations considered passed the standard QA checks. The representativeness of the station location and set-up especially in cities (often on roof buildings), however, is often poor (Piringer et al., 2005). Measurements are thus assumed to represent $2 \mathrm{~m}$ temperature and $10 \mathrm{~m}$ winds without any height corrections. In the LM, the corresponding $2 \mathrm{~m}$ temperature and $10 \mathrm{~m}$ winds are derived diagnostically from surface and lowest model layer values in the constant flux layer using improved stability functions which are neither derived from Monin-Obukhov similarity theory nor measurements but from the LM turbulence closure (Mellor and Yamada, 1974). Some meteorological parameters are also modelled as instantaneous values while the measurements are reported as time averages (like wind speed and direction, reported as $10 \mathrm{~min}$ or hourly averages). Additionally, representativeness is influenced by the largely diverging volumes for the station observations and the model grid boxes which also differ by a factor of about 70 for the lowest grid box between the LM with 7 and $1.1 \mathrm{~km}$ resolution. With increasing model resolution and detail of the simulations, traditional verification approaches at fixed stations are degraded (compared to larger scale forecasts and despite improved mesoscale structures) by model time and space errors and deficiencies of the observing network, e.g. data scarcity and representativeness problems (Mass et al., 2002, see also for a comprehensive discussion of mesoscale model predictability). The operational $7 \mathrm{~km} \mathrm{LM}$ forecast equations and results are evaluated in the daily NWP process while the higher resolution simulations must remain inadequate due to known deficiencies of not yet scale-adapted and non-urbanised physiographic parameters and physical parameterisations. Important microscale effects of urban structure (like street canyons) are neither resolved nor yet parameterised in the Lokalmodell.

These aspects cast considerable uncertainty on model validation against point measurements. Therefore, deterioration of model evaluation at station locations with increasing model evaluation must not necessarily deny model improvement. It was thus important to broaden the evaluation by considering the consistent behaviour of the meteorological fields in space and time for judging model improvements (Skouloudis, 2000; Mass et al., 2002). For these reasons, but also due to the restricted amount of data available for the episodes, statistical scores at observation stations are not presented here. The episode error ranges, however, were 
Table 1. Meteorological episode charateristics.

Episode simulation
(full episode)

Helsinki

27-29 Dec 1995

Helsinki

22-24 March 1998

(21-31 March 1998)

Helsinki

9-11 April 2002

(8-13 April 2002)

Oslo

17-19 Nov 2001

(12-22 Nov 2001)

Oslo

6-8 Jan 2003

(1-11 Jan 2003)

Valencia

26-30 Sep 1999

(29 Aug-1 Oct 1999)
- Local winter inversion-induced episode (with high $\mathrm{NO}_{2}, \mathrm{CO}$ and $\mathrm{PM}_{10}$ )

- Extremely strong ground-based inversion $\left(-16^{\circ} \mathrm{C}\right.$ in lowest $90 \mathrm{~m},-18^{\circ} \mathrm{C}$ in $\left.125 \mathrm{~m}\right)$, induced by long-wave radiation

- Persistent stable (even daytime!) to very stable nocturnal stratification

- High pressure, very cold $\left(-25^{\circ}\right.$ to $\left.-2^{\circ} \mathrm{C}\right)$ and mainly dry, little cloud, low to moderate westerly winds, slight snowfall on $28 \mathrm{Dec}$

- Snow cover, sea ice belt only ca. $11 \mathrm{~km}$ broad along coast

- Warm front passage on 29 Dec ends episode

- Local spring dust episode (suspended particles)

- Nocturnal ground-based inversion (induced by long-wave radiation)

- Neutral to very stable (nocturnal) stratification with strong diurnal variation

- Very high pressure, -10 to $+4^{\circ} \mathrm{C}$, dry, very low south(westerly) winds

- Melting snow

- Local spring dust episode (suspended particles from sanded streets)

- Nocturnal ground-based inversion (induced by long-wave radiation)

- Near-neutral to very stable (nocturnal) stratification with strong diurnal variation

- High pressure, very slight southeasterly winds

- Sunny and very dry, cold cloudless nights, large diurnal cycle of T2m

- No snow or ice

- Local dust episode (suspended particles, high $\mathrm{PM}_{10}$ )

- Nocturnal ground-based inversion, intermittent due to periods with stronger surface winds $(5-7 \mathrm{~m} / \mathrm{s})$ due to northwesterly foehn

- High pressure, dry, cool $\left(0^{\circ}\right.$ to $\left.9^{\circ} \mathrm{C}\right)$

- No snow or ice cover

- Inversion induced episode (highest ever Oslo $\mathrm{NO}_{2}$, high $\mathrm{PM}_{2.5}$ )

- Very strong, locally varying inversion, induced by long-wave radiation and enhanced by warm advection aloft

- High pressure, dry and very cold $\left(-18^{\circ}\right.$ to $\left.-2^{\circ} \mathrm{C}\right)$ near ground

- Snow and ice cover on ground

- Photochemical pollution episode (ozone)

- Periodic recirculation, development of mesoscale combined sea breeze/upslope wind circulations, stable conditions

- High pressure, low isobaric gradient, strong insolation 
(a)
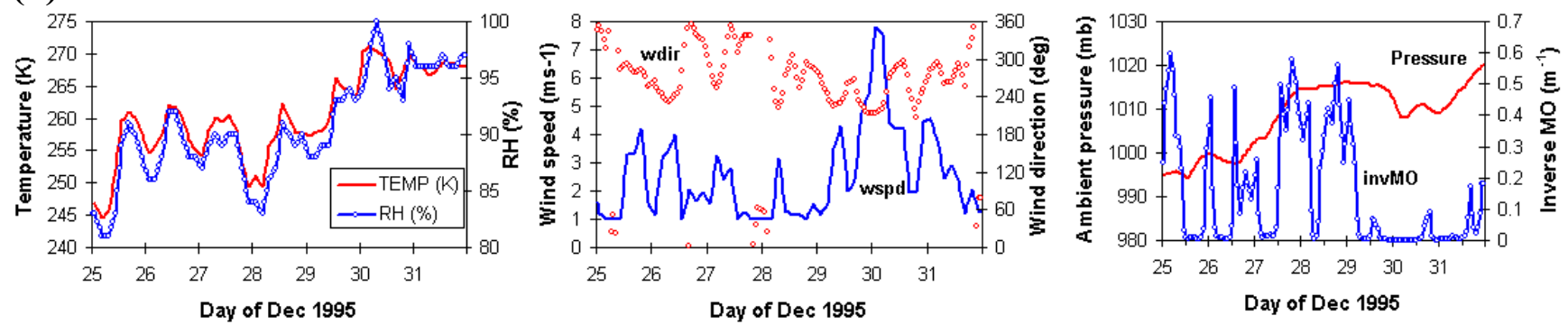

(b)
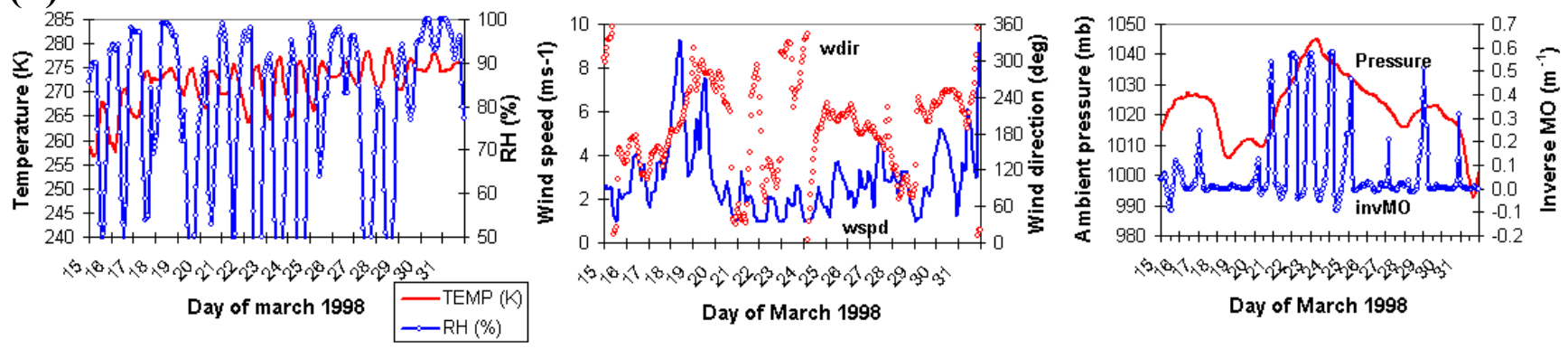

(c)
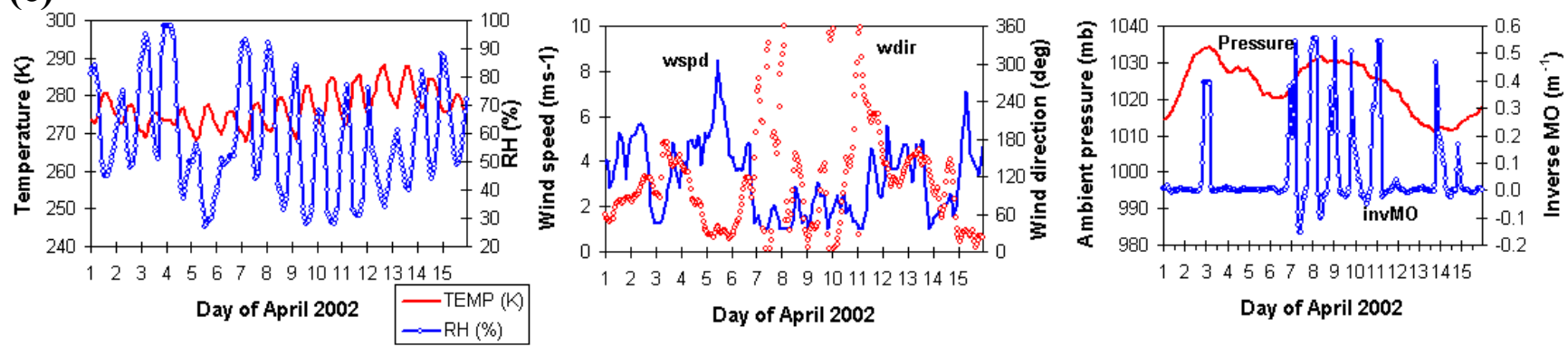

Fig. 2. Meteorological observations (plus FMI-MPP-model-derived inverse Monin-Obukhov number stability index) at Helsinki-Vantaa airport for (a) December 1995, (b) March 1998, (c) April 2002 (from FUMAPEX data web pages of the Finnish Meteorological Institute).

compared to averaged seasonal or one year scores of operational LM $7 \mathrm{~km}$ simulations for various urban regions in Fay et al. (2005).

\subsection{LM simulations for Helsinki episodes}

Especially in northern Europe, ground-based inversions caused by radiation cooling or warm-air advection aloft are the key meteorological factors leading to episodes with often very high levels of pollution. Low wind speeds and stable atmospheric stratification also play an important role in causing low ventilation and air pollution episodes as elsewhere in Europe (Sokhi et al., 2002; Pohjola et al., 2004; Rantamäki et al., 2005). Specific site topography (mountains, coast) also has a large influence, and usually high pressure anticyclonic situations prevail.

In Helsinki, episodes occur in winter and spring and particulate matter and nitrogen dioxides are the most important pollutants. The episodes investigated are local-scale, ei- ther inversion-induced or spring suspended particle episodes with nocturnal inversions. The key characteristics are inversions, atmospheric stability and low wind speeds (Kukkonen et al., 2005), but cloudiness, humidity, surface heat and radiation fluxes, and boundary layer height were also evaluated. The extreme winter inversion episode of December 1995 was due to long-wave radiation cooling of the snow-covered ground. The episode days for the March 1998 and April 2002 episodes are classified as suspended particle episodes. Meteorological observations and a measurement-derived stability index (Pohjola et al., 2004, and FUMAPEX web site of the Finnish Meteorological Institute) at Helsinki-Vantaa airport are illustrated in Fig. 2 for the three episodes. The exceptionally high and persistent stability is apparent in the measurement-derived inverse Monin-Obukhov length for the extreme inversion episode of December 1995.

Before evaluating the simulations the changes in physiographic parameters with increasing LM resolution are 
(a)

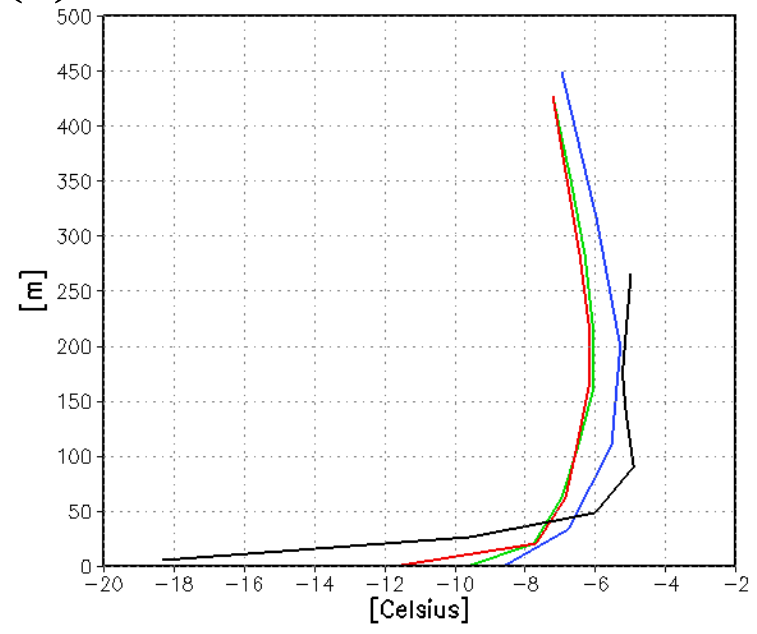

(b)

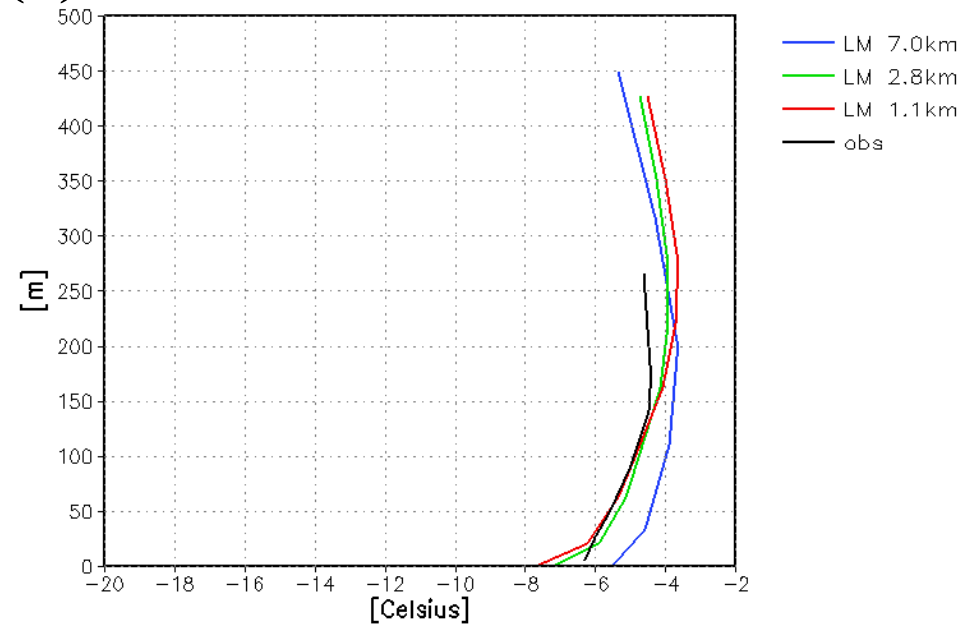

Fig. 3. Vertical profiles of forecast temperature $\left[{ }^{\circ} \mathrm{C}\right]$ for $\mathrm{LM} 7.0 \mathrm{~km}, 2.8 \mathrm{~km}, 1.1 \mathrm{~km}$ grid resolution for Kivenlathi mast including observations on 28 December 1995, 00:00 UTC (a) $+6 \mathrm{~h}$ and (b) $+36 \mathrm{~h}$.

Table 2. Change of LM physiographic parameters with increasing LM resolution at Helsinki observation stations (in brackets number of national station). Surface soil type for the grid point nearest station: $3=$ sand, $4=$ sandy loam, $6=$ clayey loam, $9=$ water.

\begin{tabular}{|c|c|c|c|c|c|c|c|c|c|c|}
\hline \multirow[t]{2}{*}{$\begin{array}{l}\text { WMO station } \\
\text { (national no.) }\end{array}$} & \multirow[t]{2}{*}{ Station name } & \multirow[t]{2}{*}{ Lat } & \multirow[t]{2}{*}{ Lon } & \multirow[t]{2}{*}{$\mathrm{H}[\mathrm{m}]$} & \multicolumn{3}{|c|}{$\begin{array}{l}\text { Surface land cover } \\
\text { Fraction of grid point }\end{array}$} & \multicolumn{3}{|c|}{ Surface soil type } \\
\hline & & & & & $7.0 \mathrm{~km}$ & $2.8 \mathrm{~km}$ & $1.1 \mathrm{~km}$ & $7.0 \mathrm{~km}$ & $2.8 \mathrm{~km}$ & $1.1 \mathrm{~km}$ \\
\hline 2988 & Isosaari & 60.10 & 25.07 & 5 & 0 & 0 & 0 & 9 & 9 & 9 \\
\hline 2963 & Jokioinen & 60.82 & 23.50 & 103 & 0.99 & 1 & 1 & 6 & 6 & 6 \\
\hline 2978 & Kaisaniemi & 60.17 & 24.94 & 4 & 0.32 & 0.34 & 0.84 & 9 & 9 & 3 \\
\hline (0334) & Kivenlahti & 60.18 & 24.65 & 44 & 0.82 & 0.95 & 1 & 3 & 3 & 4 \\
\hline 2974 & Vantaa & 60.32 & 24.97 & 56 & 1 & 1 & 1 & 4 & 6 & 6 \\
\hline
\end{tabular}

discussed. For the rather flat Helsinki area, orographic heights remain below $200 \mathrm{~m}$ for all resolutions. The influence of higher resolution physiographic parameters for the inner LM nest is most evident in the much more indented coast line. Table 2 lists the changes with increasing resolution in land/sea mask and soil type at the Helsinki observation stations. Both are remarkably influenced by grid resolution caused by an increasing number of LM grid points changing from sea to land points in the direct vicinity of the observation stations. The decimal land cover value reflects the proportional influence of land and sea grid points at the station location. The island of Isosaari is too small to be described as a land point even in the highest resolution of $1.1 \mathrm{~km}$. Kaisaniemi is located near Helsinki harbour, and the land fraction is clearly increasing with resolution. For the surface soil type, the value of the nearest grid point is listed. The changes in Kaisaniemi, Kivenlahti and Vantaa directly influence the soil-dependent physiographic parameters (e.g. heat conductivity, heat capacity, field capacity) and lead to the changes in e.g. the heat and moisture budget of the model described below (Neunhäuserer and Fay, 2004).

\subsubsection{Evaluation of temperature, inversions, stability and wind fields}

The 1995 Helsinki episode is caused by an exceptionally persistent, strong and shallow ground-based inversion. The inversion strength amounted to $18^{\circ} \mathrm{C}$ in the lowest $125 \mathrm{~m}$ for the Jokioinen sounding and $16^{\circ} \mathrm{C}$ in $91 \mathrm{~m}$ at the Kivenlahti mast on 28 December 1995, 01:00 UTC when the snowcovered ground was cooled extensively by long-wave radiation under a clear sky (Rantamäki et al., 2005). A similar inversion intensity was not reported previously in other European urban areas (Piringer and Kukkonen, 2002). Inversions persisted to a lesser extent even during the daytime until the evening of 29 December when they dissolved under warm front influence. The ability of the model to reproduce these dominating feature is investigated first. Figure 3 shows vertical temperature profiles at the Kivenlahti radio tower for LM 
(a)

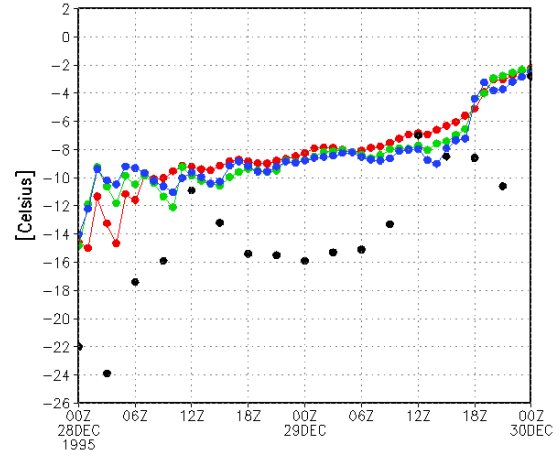

(b)

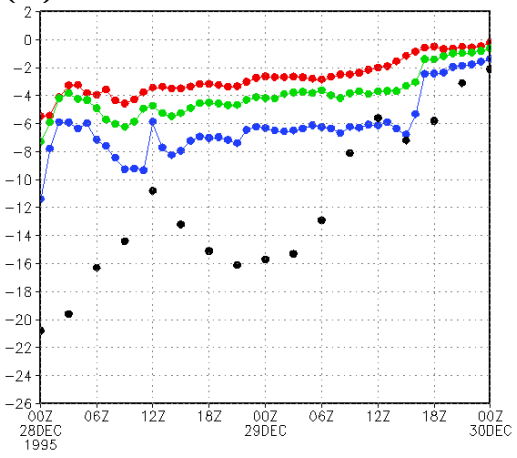

(c)

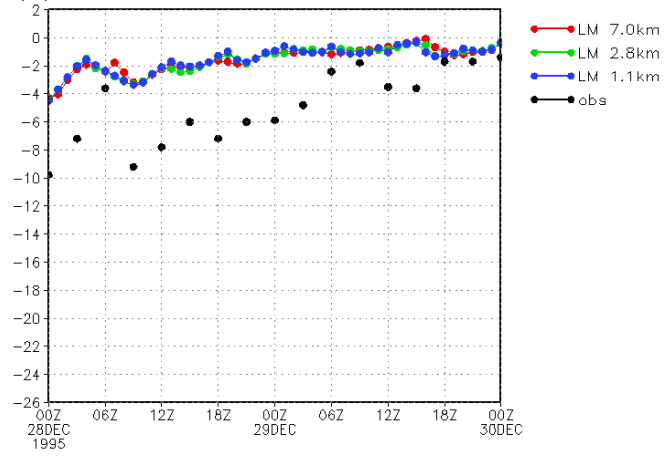

Fig. 4. Time series of $2 \mathrm{~m}$ temperature $\left[{ }^{\circ} \mathrm{C}\right]$ for $48 \mathrm{~h} \mathrm{LM}$ forecasts for $7.0 \mathrm{~km}, 2.8 \mathrm{~km}, 1.1 \mathrm{~km}$ resolution starting 28 December 1995 , 00:00 UTC, for (a) Vantaa, (b) Kaisaniemi, (c) Isosaari.

at $7.0 \mathrm{~km}, 2.8 \mathrm{~km}$ and $1.1 \mathrm{~km}$ grid resolution, compared to station observations. The inversion itself is captured by the model. The inversion strength is underestimated with each of the three grid resolutions for the extreme inversions during the night of 28 December, reaching up to $+18^{\circ} \mathrm{C}$ for the $2 \mathrm{~m}$ temperature at Jokioinen and Kaisaniemi. This overprediction decreases with increasing model resolution but still exceeds $7^{\circ} \mathrm{C}$ in the best case. The less intense daytime inversion on 29 December 1995, 12:00 UTC (Fig. 3b), is much better described and even overpredicted in strength for the higher model resolutions.

Figure 4 compares the $2 \mathrm{~m}$ temperature results of LM for the 28 December 1995 forecasts to station observations. The large diurnal temperature variation is not simulated in the wintertime episode. Nevertheless, while there is little change due to grid refinement in Vantaa and Isosaari, the Kaisaniemi results move from the sea characteristics of the Isosaari temperatures to the inland values at Vantaa with increasing resolution. The same behaviour is found for sensible and latent heat fluxes. This confirms the positive impact of the increasing land fraction on the physiographic parameters for the LM grid points representing Kaisaniemi as shown in Table 2. On the other hand, Isosaari has no diurnal temperature cycle for any LM resolution as it always remains a sea location.

In an attempt to explain the large temperature bias of LM especially for the nocturnal minima during the inversions, several meteorological factors are studied in the following paragraphs.

Large initial forecast errors often stem from model spin-up or data assimilation problems and may contribute to the poor inversion prediction. In the experiment, only 00:00 UTC forecasts are used but the strongest inversions and temperature minima occur around 00:00 UTC for the episode. There is no surface data assimilation of temperature in LM, but soil moisture, sea surface temperature and snow height are analysed at the start of the 00:00 UTC predictions which are used in this study. The short forecast with recent data assim- ilation and initialisation may even improve slightly for the $2 \mathrm{~m}$ temperatures around 00:00 UTC (near-minimum temperature) compared to the medium and long forecast of $24 \mathrm{~h}$ or $48 \mathrm{~h}$ previously. A spin-up error may thus contribute to the deviations but is usually small compared to observed nearsurface errors of up to $11^{\circ} \mathrm{C}$.

Cloud cover has a strong influence on long-wave cooling of the surface and is investigated as far as observation records permit. The detected small deficiencies in the forecast of cloud cover and hence the effect on long-wave radiation are likely to contribute only slightly to the overall temperature and inversion error in the December 1995 episode.

A snow cover was observed and is also analysed and forecasted in LM. Snow height in LM referred to loose powder snow independent of age, density, heat capacity and conductivity which may influence surface temperature, vertical fluxes and consequently the development of shallow inversions (Rantamäki et al., 2005). As the influence of snow treatment in the LM soil scheme on temperature and inversion prediction was suspected to be large, an increase of snow density with age and a snow albedo depending on snow age and forest cover are now operational in LM in order to improve the thermal effects on the $2 \mathrm{~m}$ temperature. Additionally, an improved 7 layer soil scheme with freezing and melting of soil water and ice was introduced.

A narrow belt of (mainly new) sea ice of $11 \mathrm{~km}$ width was observed on the Gulf of Finland near Helsinki (Ice chart No. 29.12.1995 of Finnish Institute of Marine Research). No ice cover at all was simulated with the LM which uses sea ice information assimilated in the global model GME because the observed ice belt was not detected in the coarse GME assimilation grid, but improvements of sea-ice effects in LM are under development. Rantamäki et al. (2005) conclude from sensitivity studies that the ice cover on the Gulf of Finland may have a substantial effect on surface parameters. This atmospheric response may be advected downwind and ashore where the effects on the planetary boundary layer 
(a)

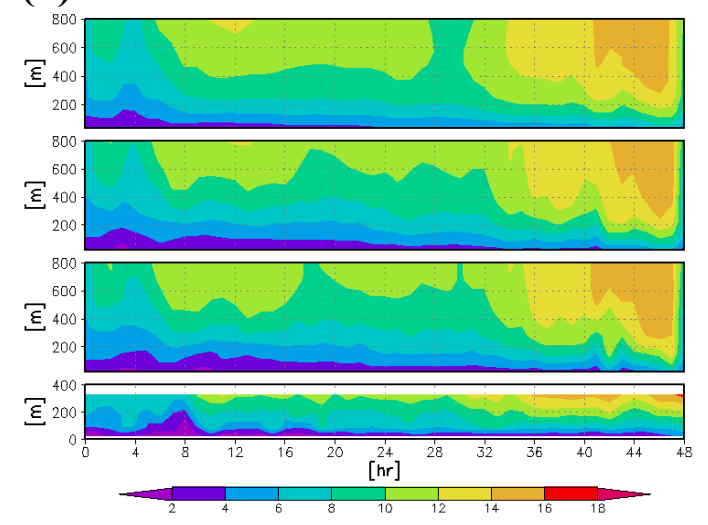

(b)

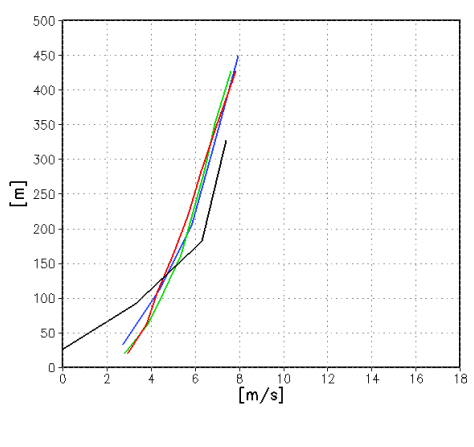

(c)

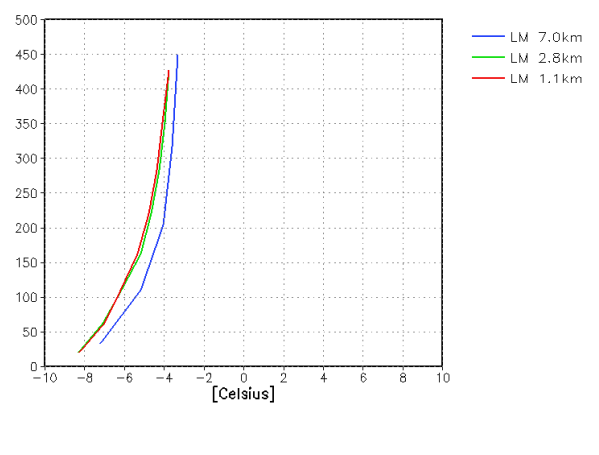

Fig. 5. Vertical profiles of (a) horizontal wind speed [m/s] as $48 \mathrm{~h}$ time series at Kivenlathi mast for LM 7.0 km, $2.8 \mathrm{~km}, 1.1 \mathrm{~km}$ grid resolution and observations (top to bottom), (b) wind speed [m/s] for 28 December 1995, $+6 \mathrm{~h}$, (c) potential temperature [ $\left.{ }^{\circ} \mathrm{C}\right]$ for 28 December 1995 , 00:00 UTC +6 h.

can be crucial for air quality applications (Drusch, 2005). In $\mathrm{LM}$, the proximity to comparatively warm open water instead of the observed ice cover directly influences meteorological parameters at the coastal grid points. This adds to the necessity to investigate wind speed and direction observations and forecasts carefully even in this radiation-induced inversion episode.

The correct simulation of low model wind speeds and sufficient atmospheric stability are the further key requirements for correct inversion episode forecasting and are closely connected to inversion modelling. Synoptic westerly winds are observed above the inversion together with unusually warm air caused by warm advection and anticyclonic subsidence. Vertical profiles of wind direction show a southerly bias in LM forecasts compared to measurements. The vertical profiles of horizontal wind speed shown in Figs. 5a-b exhibit a frequent shape especially for the winter episodes with overestimation of velocity near the surface and underestimation aloft. This comparison indicates overpredicted vertical exchange and insufficient LM stability. The unusually warm air aloft would then be mixed down and contribute to the temperature overprediction near the surface. Evaluation of $10 \mathrm{~m}$ winds in Fig. 6 reveals varying performance of $10 \mathrm{~m}$ horizontal wind speeds. The pattern of larger wind speed variations is captured, with the forecast improving with increasing grid resolution as for 29 December 1995, belonging to the warm front passing Helsinki and marking the end of the episode (Figs. $6 \mathrm{~b}-\mathrm{c}$ ). Slight wind velocity values are overpredicted at all stations especially in the strongest inversion night of 27 to 28 December and calms are not forecasted at all (Figs. 6a-c). This again points to insufficient stability for the episode simulations as discussed above. LM vertical profiles of potential temperature, however, demonstrate strong to very strong thermal stability at the inland stations and mainly stable and some neutral stratification at the coastal stations of Kaisaniemi and Isosaari (Fig. 5c). There is, however, a temporal decrease of stability on 28 December, 00:00 UTC, at all stations. On the other hand, for very stable winter episodes, the overestimation of $2 \mathrm{~m}$ temperatures and $10 \mathrm{~m}$ winds may be due to suspected insufficient stability influence on the transfer coefficients and the introduction of minimum diffusion coefficients for stable situations in LM causing overestimation of vertical exchange that reduces the overall inversion strength. For strong inversions, $2 \mathrm{~m}$ temperature may also be overestimated by specific features of the stability-dependent interpolation between surface and the lowest prognostic level in the LM (Neunhäuserer et al., 2004).

The overprediction of very slight wind speeds or a lack of calms may have a great influence in regions of large temperature contrasts as between the very cold land mass and the unfrozen sea. Erroneous temperature advection might then seriously change the simulated meteorological and pollution conditions of this basically local episode. Forecasts of wind direction must then also be investigated as an additional cause or explanation of the model failure to simulate the inversions.

During the strongest inversion night of 27 to 28 December, calms or low winds $<2.5 \mathrm{~m} / \mathrm{s}$ are observed at the stations (with only one exception of $7 \mathrm{~m} / \mathrm{s}$ at the island station Isosaari on 28 December, 06:00 UTC, presumably due to direct sea influence). The lower boundary layer winds were also weak, at least up to the $100 \mathrm{~m}$ level for the Kivenlahti mast (Rantamäki et al., 2005). These wind speeds are overpredicted with all LM versions. In Vantaa e.g., there is a calm in $10 \mathrm{~m}$ winds from 27 December, 18:00 UTC, until 28 December, 03:00 UTC, while the LM with all resolutions simulates mainly southwesterly (to southeasterly) winds between $1-2.5 \mathrm{~m} / \mathrm{s}$ (Figs. 6a, d) which advect comparatively warm and moist sea air from the Baltic $(11 \mathrm{~km}$ ice belt observed, 
(a)

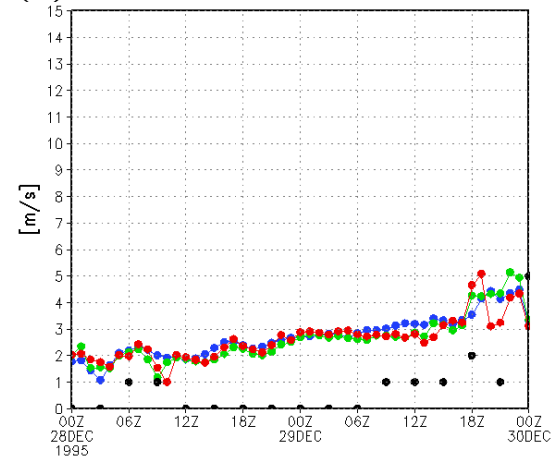

(d)

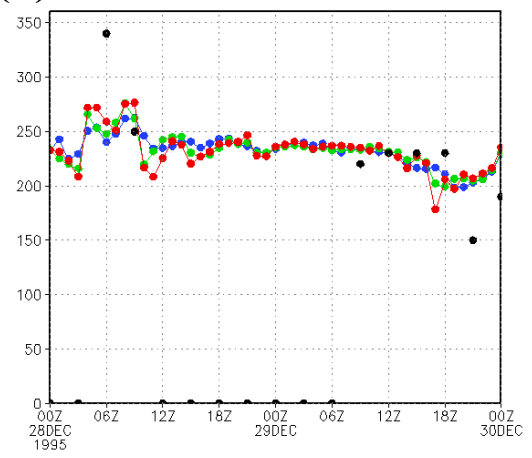

(b)

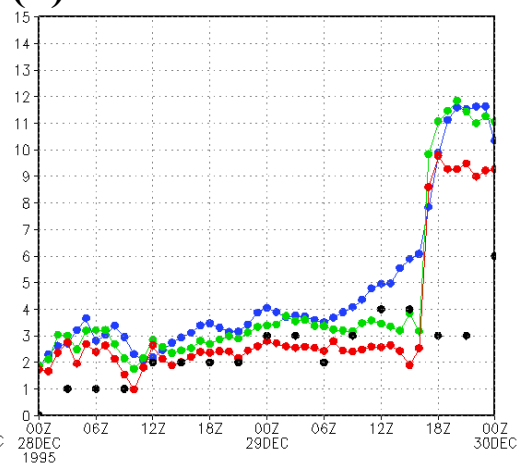

(e)

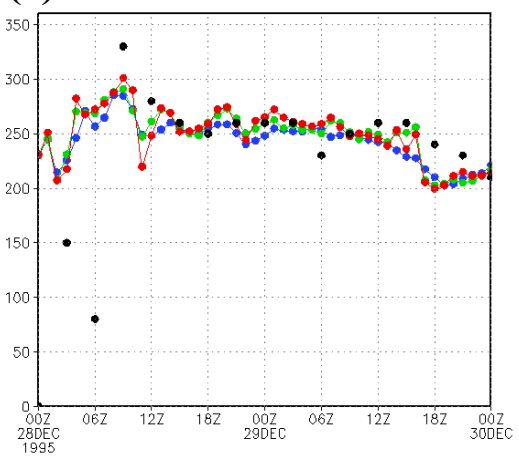

(c)

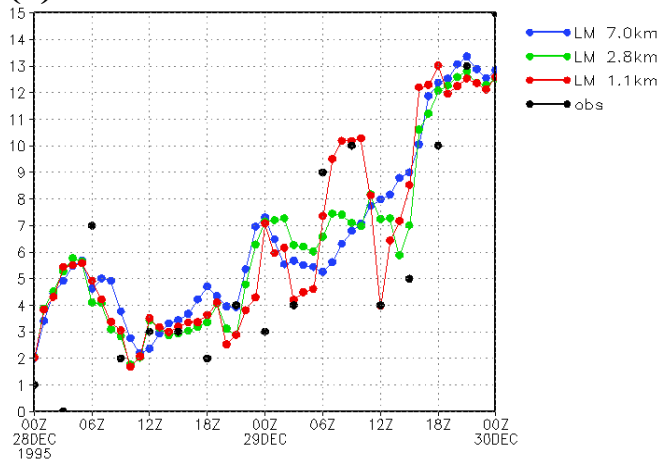

(f)

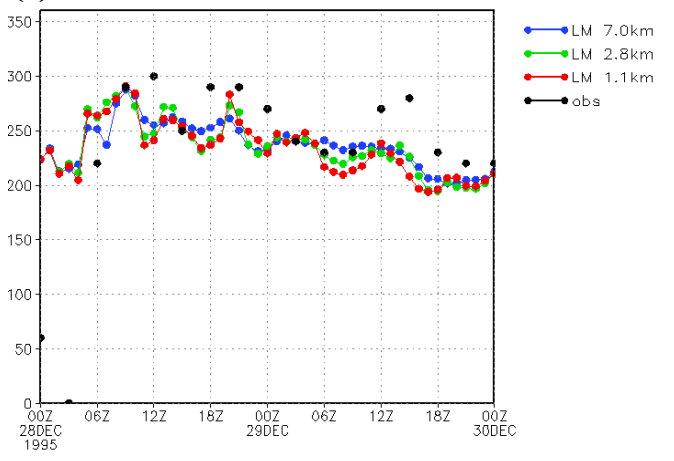

Fig. 6. Time series of $10 \mathrm{~m}$ horizontal wind fields for $48 \mathrm{~h} \mathrm{LM}$ forecasts for $7.0 \mathrm{~km}, 2.8 \mathrm{~km}, 1.1 \mathrm{~km}$ resolution starting 28 December 1995 , 00:00 UTC, top: wind speed [m/s] for (a) Vantaa, (b) Kaisaniemi, (c) Isosaari, and bottom: wind direction for (d) Vantaa, (e) Kaisaniemi, (f) Isosaari.

with no ice in $\mathrm{LM}$ ) in the nocturnal hours around the inversion maximum (Fig. 4a) when the $2 \mathrm{~m}$ temperature is overpredicted by $10^{\circ}$ to $12^{\circ} \mathrm{C}$ in the LM versions. Very similar situations prevail at Kaisaniemi (Figs. 6b, e) and Kivenlahti stations. At the harbour station Kaisaniemi with the largest $2 \mathrm{~m}$ temperature errors of $+14^{\circ} \mathrm{C}$ to $+18^{\circ} \mathrm{C}$, the forecast may additionally deteriorate due to the immediate coastal situation at the open ice-free LM Baltic instead of the sea ice belt in combination with reduced stability and additional overprediction of vertical exchange, wind speed and warm advection. The neighbouring grid points also partly remain sea points with incorrect physiographic parameters (see Table 2).

The simulated temperature development at all stations seems sensitive to the combined error in wind speed and northerly or southerly deviations from observed winds and, correspondingly, insensitive even to large errors of wind speed as long as the wind direction is correctly simulated. The missing diurnal cycle of temperature and nocturnal temperature minimum in all LM station forecasts from 28 December, 00:00 UTC, corresponds to underpredicted stability and overpredicted vertical exchange and wind speeds combined with wind directions in favour of the southwesterly, i.e. seaward direction from the basically unfrozen Gulfs of Finland and Bothnia. Even the island station Isosaari, which is a LM sea grid point, shows this dependency although to a lesser extent (Figs. 6c, f).

In conclusion, the large nocturnal errors of LM forecasts of near-surface temperatures and inversions experienced especially on 28 December may be caused by a whole range of factors that interact in a highly non-linear way and partly intensify. These include insufficient stability influence on transfer and diffusion coefficients, overestimated vertical exchange and mixing- down of warm air from aloft, reduction of strong stability, erroneous lower level warm advection due to errors in wind speed and direction in an area of large temperature contrasts, lack of sea ice for the episode, and deficiencies in the snow treatment in the LM soil scheme and partly in physiographic parameters as well.

As Helsinki is positioned outside the operational LM domain, no long-term performance scores are available. Overprediction of $2 \mathrm{~m}$ temperature of $>10^{\circ} \mathrm{C}$ is far beyond the $2^{\circ} \mathrm{C}$ bias that is considered satisfactory for the typical LM temperature forecast. The December 1995 Helsinki episode is thus certainly not only the most extreme inversion episode observed in southern Finland but also an extreme case of poor model performance for the LM. Poor performance is reported for other NWP models like MM5, HIRLAM and RAMS (Berge et al., 2002; Pohjola et al., 2004; Fay et al., 2004; 
(a)
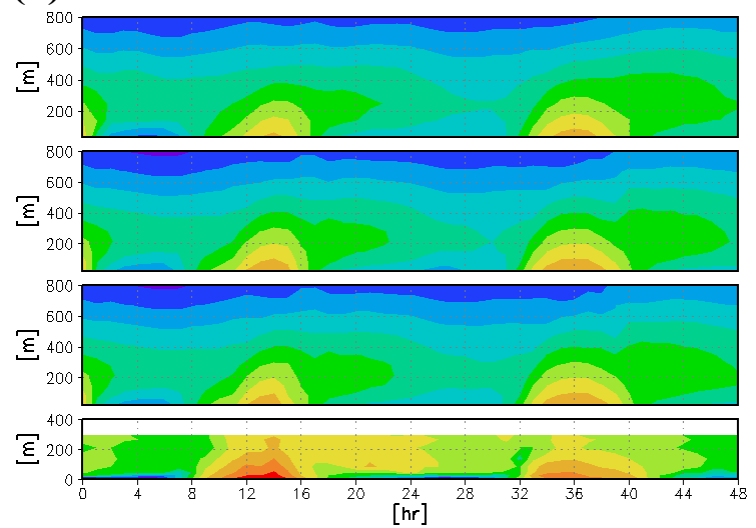

(c)

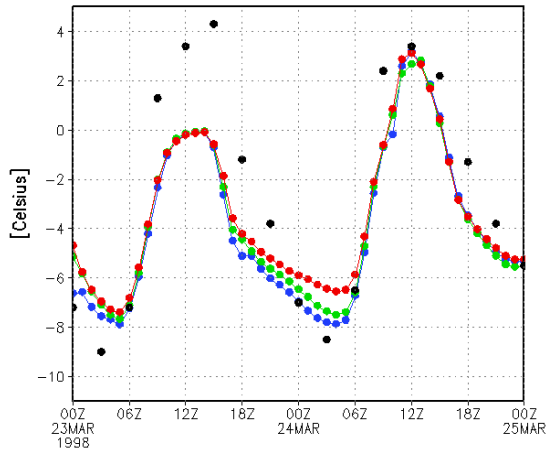

(d)

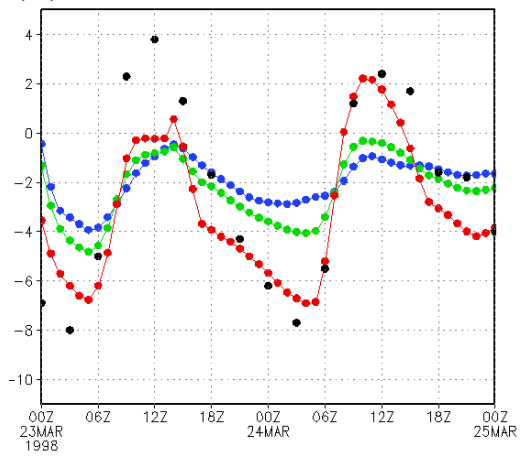

(b)
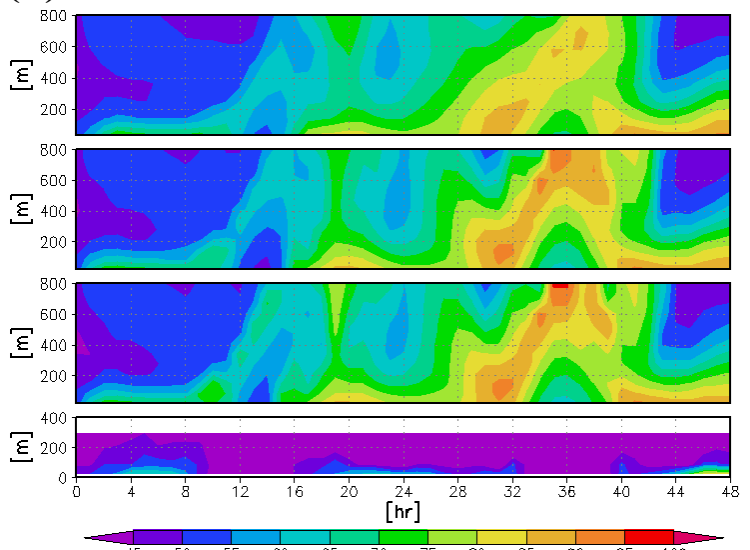

(e)

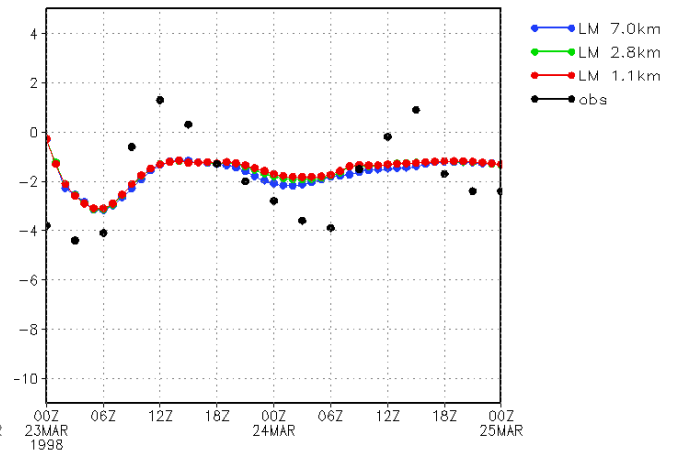

Fig. 7. LM $48 \mathrm{~h}$ forecasts for $7.0 \mathrm{~km}, 2.8 \mathrm{~km}, 1.1 \mathrm{~km}$ resolution starting 23 March 1998, 00:00 UTC, and observations. Top: Vertical profiles as $48 \mathrm{~h}$ time series for (a) temperature $\left[{ }^{\circ} \mathrm{C}\right]$ and (b) relative humidity [\%] (top to bottom: $7.0 \mathrm{~km}, 2.8 \mathrm{~km}, 1.1 \mathrm{~km}$, observations). Bottom: $48 \mathrm{~h}$ time series of $2 \mathrm{~m}$ temperature $\left[{ }^{\circ} \mathrm{C}\right]$ for (c) Vantaa, (d) Kaisaniemi, (e) Isosaari.

Rantamäki et al., 2005) for this strong inversion episode as well.

In both spring episodes, the observed ground inversions are still stronger at night with inversion strengths of up to $8^{\circ} \mathrm{C}$ but lift and disappear during the day. Exemplary vertical profiles for 23 March 1998 in Fig. 7a show that the largest temperature errors are now found in the upper part of the inversion layer, not near the surface, but are reduced to below $5^{\circ} \mathrm{C}$. Temperatures are generally underpredicted in the whole lower troposphere from the ground upwards, except in some nocturnal inversions. Additionally, the amplitude of the diurnal temperature cycle especially at the ground, but also aloft is generally underpredicted. This points to the typical springtime LM tendency of premature thaw and exceeding soil moisture in the upper soil level leading to exceeding latent heat fluxes, overpredicted relative humidity in the lower boundary (Fig. 7b) and underpredicted temperatures.

The less extreme spring episodes, nevertheless, show improved near-surface temperature forecasts for all LM resolutions with deviations mainly below $4^{\circ} \mathrm{C}$ even in the nocturnal inversions. The diurnal variation of the $2 \mathrm{~m}$ temperature is well developed at inland stations in spring (Fig. 7c) but maxima are often underpredicted due to the exceeding upper soil moisture. Only at the island station Isosaari the amplitude of the diurnal cycle remains underpredicted because the station is a sea grid point in LM (Fig. 7e). The results at the near-harbour station Kaisaniemi benefit clearly from the growing land fraction and improved physiographic parameters as the diurnal cycle is best captured with the highest resolution (Fig. 7d). Diurnal cycles for sensible and latent heat fluxes are also developed with increasing resolution and land fraction as well. Wind speed forecasts tend towards overprediction of low wind speeds and underprediction of larger ones. Deviations in wind direction may still be large but their influence on temperatures is reduced due to the diminished temperature contrasts in the region in spring.

\subsubsection{Evaluation of boundary layer and inversion heights}

Further key thermodynamic factors for pollutant episodes are atmospheric stability and boundary layer height. Strong stability is predominant especially in northern inversion episodes where strongly stable stratification may persist even 
(a)

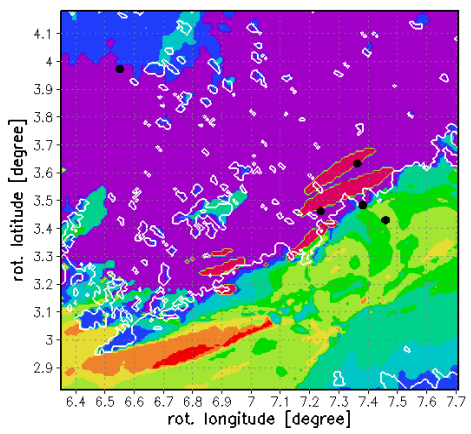

(b)

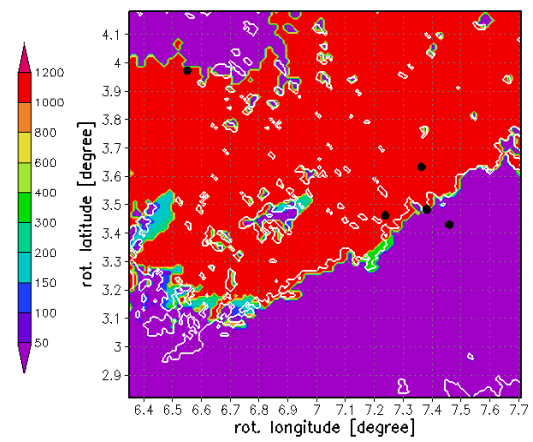

(c)

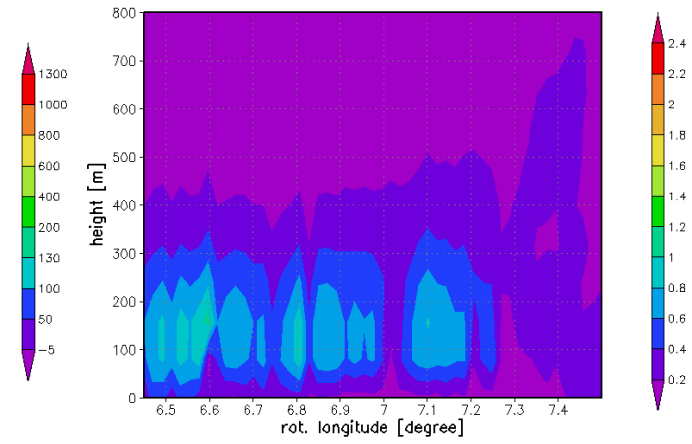

Fig. 8. Horizontal fields of boundary layer height $[\mathrm{m}]$ calculated with the gradient Richardson number scheme for the $1.1 \mathrm{~km}$ LM forecast for 28 December 1995, 00:00 UTC $+12 \mathrm{~h}$. (a) daytime mixing height showing mainly undefined values in violet, (b) stable nocturnal scheme without replacement strategy showing mainly undefined values (below $1200 \mathrm{~m}$ ) in red (c) vertical cross section of turbulent kinetic energy $\left[\mathrm{m}^{2} / \mathrm{s}^{2}\right]$ through Jokioinen (near left margin of figure) and Kivenlahti (near right margin).

during most of the day like for the extreme inversion episode of December 1995 (Fig. 2a). The stability of the PBL characterises the dispersion qualities in the boundary layer while PBL height determines the volume available for pollutant dispersion and the resulting concentrations and thus is one of the fundamental parameters in many dispersion models.

At the DWD, the operational gradient Richardson number scheme based on the diagnostic version of the turbulence parameterisation scheme of LM (following Mellor and Yamada, 1974, level 2) was evaluated with good results in a wide variety of synoptic situations (Fay et al., 1997). For the extremely strong and shallow inversion-induced 1995 wintertime episode the determination of pollutant-relevant "mixing" heights is difficult. The continuous Kivenlahti mast observations and the Jokioinen soundings show a quasipermanent ground inversion up to $100-200 \mathrm{~m}$ rising to 400 $500 \mathrm{~m}$ for Jokioinen soundings at 12:00 UTC on 28 December (Rantamäki et al., 2005). Strongly stable conditions persist almost continuously from 27 December up to the noon of 29 December with the maximum inversion strength during the night of 28 December (Fig. 3a). Thus even during the day, a stability situation typical for the stable nocturnal inversion is retained (Zilitinkevitch et al., 2002). Pollutants are probably trapped to a greater part under this inversion causing the episode. On the other hand, warmer air from advection and subsidence remains aloft. Boundary layer heights derived from LM vertical profiles of potential temperature show inversion heights of between 200 and $300 \mathrm{~m}$ for Jokioinen and Kivenlahti. LM potential temperature profiles also describe a decline of the very strong stability above the inversion but with strong stability still found in all higher levels. Deriving boundary layer heights with a turbulent kinetic energy (TKE) depletion approach (using a 5 or 10 per cent depletion criterion) on the LM TKE cross section shown in Fig. 8c would lead to more appropriate values rising above $400 \mathrm{~m}$ inland near Jokioinen at 12:00 UTC. This contrasts with results of
Baklanov (2000), where stable inversions were largely underestimated with the TKE depletion approach for the CPR turbulence scheme and confirms that the approach is also very sensitive to the turbulence scheme.

The Richardson number scheme for the daytime mixing height, however, describes a noon boundary layer height of up to $1200 \mathrm{~m}$ mainly along the coast that might belong to a higher "rural" or elevated residual boundary layer on top of the shallow inversion. Mixing heights remain undefined at many grid points (Fig. 8a, violet colour) because the Richardson number scheme for the synoptic daytime mixing height is based on the detection of the transition between a dynamically and thermally unstable layer to a stable one. It is thus unable to describe a boundary layer in stable stratification extending high into the troposphere. Further investigations show that the stable stratification at most undefined points extends above $1000 \mathrm{~m}$ (Fig. 8b, red colour) so that the section for determining stable PBL heights in the mixing height scheme could not be successfully applied, either.

For the 1998 spring episode, the typical diurnal cycle of rising $\mathrm{BL}$ height during the near-neutral daytime conditions is simulated, with noon or afternoon maxima and a collapse towards the nocturnal stable heights. Mixing heights increase from lower coastal values of $200 \mathrm{~m}$ to inland heights of $600-800 \mathrm{~m}$ on 24 March and $1000-1200 \mathrm{~m}$ on 25 March at 12:00 UTC. They agree with vertical profiles of LM potential temperature and turbulent kinetic energy (TKE depletion approach) and validate well in comparison with Jokioinen radiosoundings and with further mesoscale models in FUMAPEX. The development of the mixing heights is found to be delayed and slightly reduced $(100 \mathrm{~m})$ due to overpredicted cloud cover and the effects of premature LM thaw which lead to exceeding moisture in the upper soil level, reduced $2 \mathrm{~m}$ temperature, sensible heat flux and mixing heights. The mixing heights for 10 April 2002 show the same overall behaviour but increased maximum heights of 
(a)

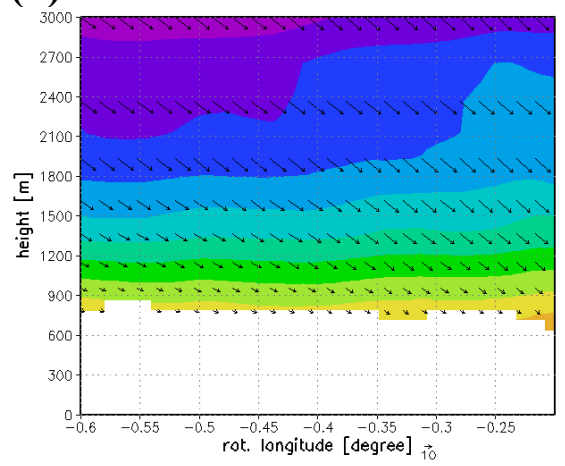

(d)

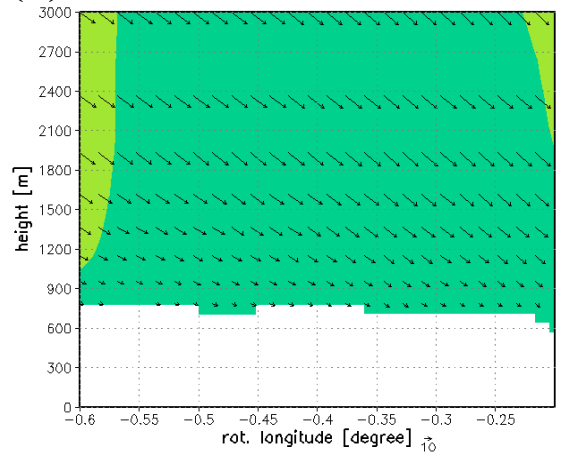

(b)

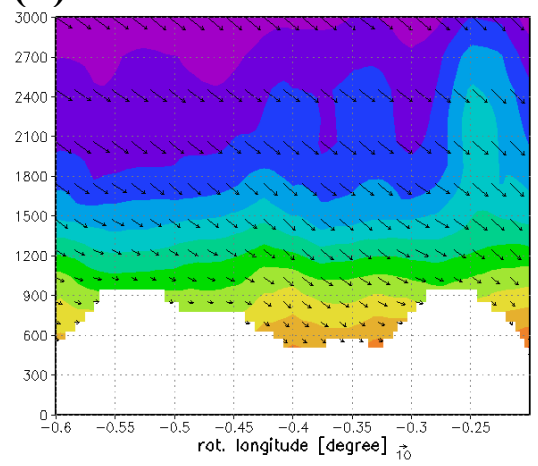

(e)

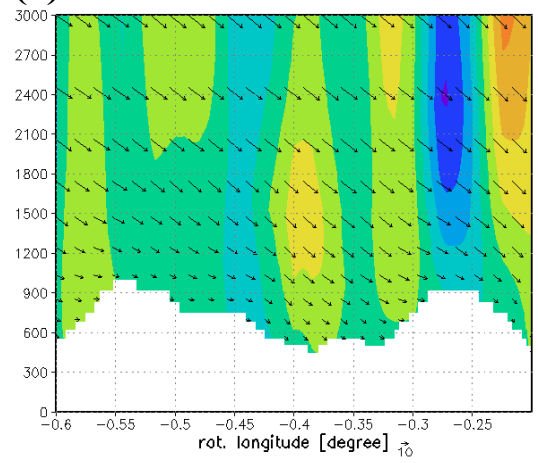

(c)

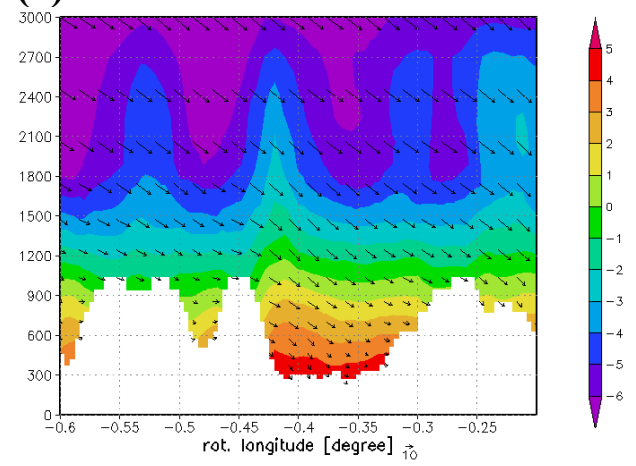

(f)

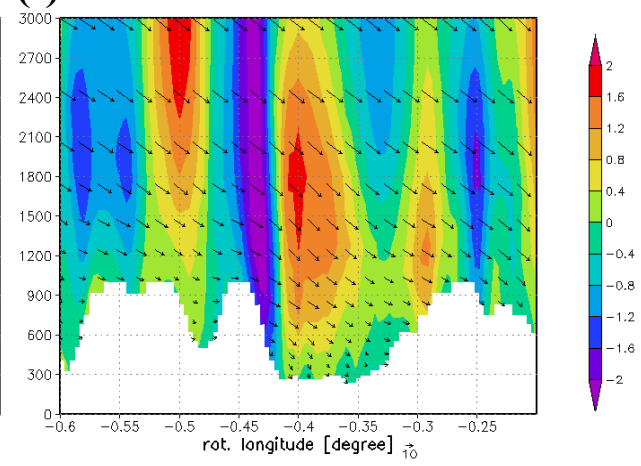

Fig. 9. Oslo forecasts with LM of 7, 2.8, $1.1 \mathrm{~km}$ resolution, 17 November 2001, 00:00 UTC $+18 \mathrm{~h}$. Vertical cross section along Hallingdal valley with horizontal wind speed and direction (black arrows) and shaded $(\mathbf{a}-\mathbf{c})$ temperature $\left[{ }^{\circ} \mathrm{C}\right],(\mathbf{d}-\mathbf{f})$ vertical velocity $[\mathrm{m} / \mathrm{s}]$.

1400-1500 $\mathrm{m}$ due to higher temperatures. The comparison with radiosoundings even improves due to the correct forecast of cloud cover and absent snow.

The LM gradient Richardson number scheme for mixing heights is thus capable of simulating daytime mixed boundary layer heights well for the Helsinki spring episodes with slightly unstable to near-neutral stability. It necessarily fails for the very stable daytime conditions during the December 1995 episode. However, inversion heights derived from vertical profiles of LM TKE and potential temperature succeed in simulating observed heights. These results highlight the general problems of simulating boundary layer or inversion heights under stable conditions even in the rural environment (independent of questions of urban mixing heights and internal boundary layers) and the need for improved schemes and model parameterisations especially for stable (not only nocturnal) conditions (Zilitinkevitch et al., 2002; Piringer and Joffre, 2005).

\subsection{LM simulations for Oslo episodes}

Episodes in Oslo occur in the winter half-year and are inversion-induced or suspended dust episodes. Therefore, the same key episode parameters apply as to Helsinki, i.e. ground-based inversions, stable atmospheric stratification and low wind speed, but combined with complex orogra- phy. The surrounding mountains in the shape of a large topographical basin formation worsen the dispersion conditions. The strongest inversions are observed in the valleys due to radiative cooling at the surface and often warm advection aloft, and reduced wind speeds due to sheltering in stable inversion situations when stagnant air pools form that may last for many days leading to concentration levels like in much larger European cities (Valkama and Kukkonen, 2004; Kukkonen et al., 2005). The major pollutant sources today are connected to domestic consumption (private wood and oil burning) and road traffic (road dust suspension by studded car tyres), less to long-range transport or the scarce industry.

Both Oslo episodes are local-emission episodes and distinguished by local factors (strong ground-based inversions) but also synoptic-scale dynamic features. The November 2001 episode shows intermittent breakdowns due to periods of stronger surface winds of $5-7 \mathrm{~m} / \mathrm{s}$ related to northwesterly foehn while the January 2003 ground-based inversion is mainly caused by warm advection aloft creating the strong inversion strengths of up to $20^{\circ} \mathrm{C}$ for several days. Scarce cloud cover additionally supports the formation of inversions in both episodes. For the Oslo episodes, therefore, the discussion focuses on the skill of the LM at simulating temperature, inversions, wind fields, stability and mountain sheltering of stagnant air pools. 
(a)

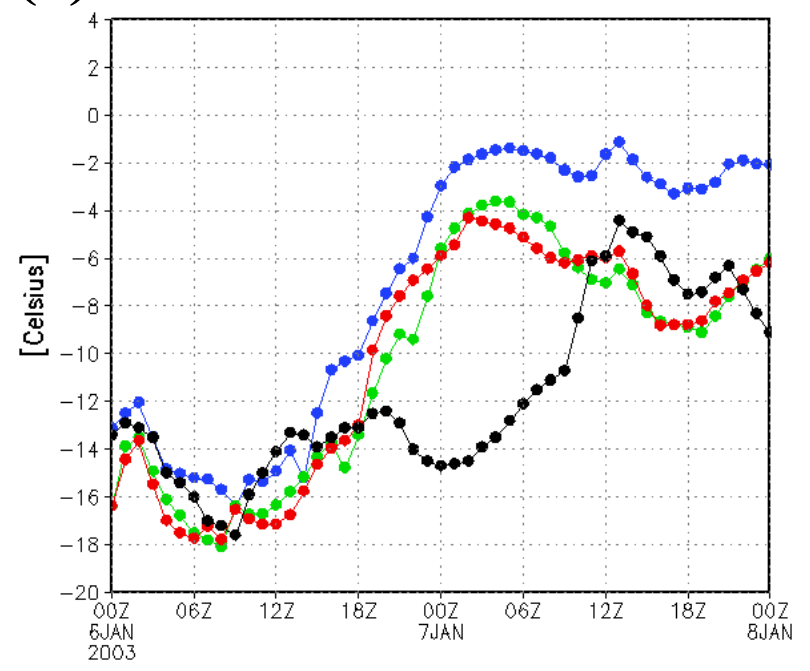

(b)

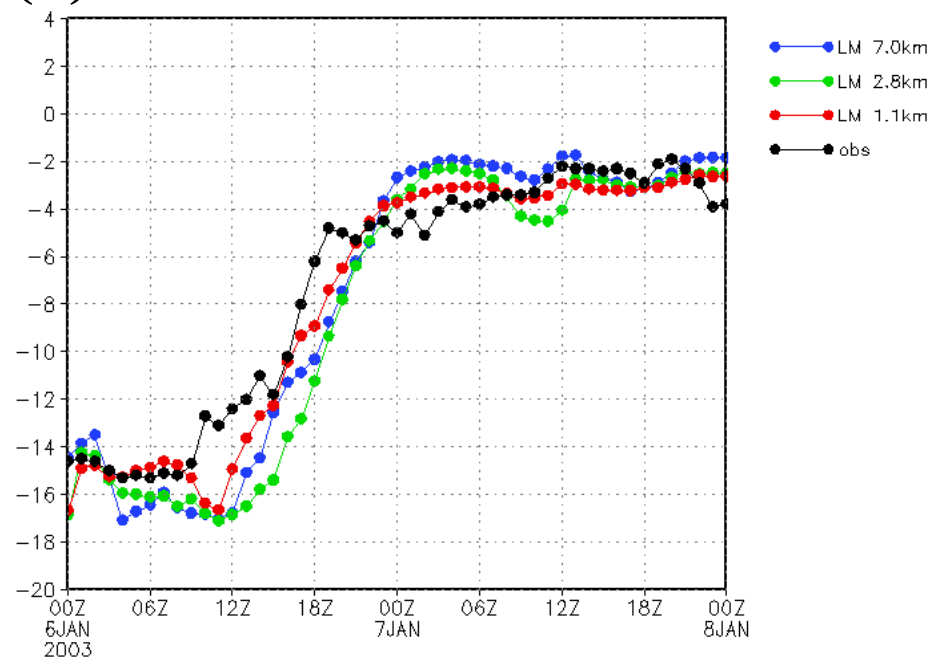

Fig. 10. Time series of $2 \mathrm{~m}$ temperature $\left[{ }^{\circ} \mathrm{C}\right]$ for LM $7.0 \mathrm{~km}, 2.8 \mathrm{~km}, 1.1 \mathrm{~km}$ and observations, $48 \mathrm{~h}$ forecast of 06 January $2003,00: 00 \mathrm{UTC}$. (a) Blindern, (b) Tryvann.

Table 3. Change of LM topographic height with increasing resolution at Oslo observation stations.

\begin{tabular}{lcllcc}
\hline \multirow{2}{*}{ Name } & \multirow{2}{*}{ Station height } & Station type & \multicolumn{3}{c}{ Model height H[m] } \\
& & & LM 7.0 km & LM 2.8 km & LM 1.1 km \\
\hline Blindern & 95 & Urban (temperature obs in 8 and 25 m) & 119 & 40 & 43 \\
Valle Hovin & 94 & Suburban & 149 & 121 & 92 \\
Tryvann & 514 & Rural hill & 249 & 285 & 442 \\
Mountain top & - & - & 1040 & 1183 & 1245 \\
Valley & - & - & 741 & 457 & 262 \\
\hline
\end{tabular}

Changes of orography with increasing LM resolution are expected to substantially influence simulations in the complex setting of Oslo between an inland fjord and nearby hills. They are listed in Table 3 for the three Oslo observation stations and two referential sites on a mountain top and in the Hallingdal valley northwest of Oslo.

All LM topographies describe the medium orography and underestimate the height differences between valleys and mountain tops even in the $1.1 \mathrm{~km}$ version. Nevertheless, the increase in horizontal grid resolution leads to a considerable improvement of the model topography. The consequences for the model results are striking, even for the cross section along the Hallingdal valley which does not include the highest mountains. The vertical temperature distribution in Figs. 9a-c exhibits deeper and warmer valleys and higher and colder mountain tops. Wind fields and streamlines become more structured and show more numerous and pronounced convergence and divergence lines. The higher and steeper orography induces mountain lee wave structures in the vertical velocity field (Figs. 9d-f). The temperature lay- ers accordingly assume a wavelike pattern of variable intensity which agrees with the northwesterly foehn observed over Oslo. This confirms the improved realism of higher resolution NWP results reported e.g. in Mass et al. (2002).

Topography influences temperature in a similar but less distinct way due to the smoother terrain and the smaller height differences at the meteorological stations in the Oslo city area. Generally, LM time series of $2 \mathrm{~m}$ temperature for the city stations show good agreement with observations and only little influence of model resolution for the November 2001 episode with temperatures between $0^{\circ}$ and $9^{\circ} \mathrm{C}$. The forecast skill for the more extreme and changeable temperatures of the January episode (initially very cold down to $-18^{\circ} \mathrm{C}$ with subsequent warm advection) is much lower. Observed temperature minima during the inversion periods are often overpredicted in the Oslo stations Blindern and Valle Hovin, up to $+12^{\circ} \mathrm{C}$ mainly during the strong inversion in the night from 6 to 7 January (Fig. 10). These errors are usually reduced with higher LM resolution. For both episodes and all LM resolutions, the diurnal temperature cycle of the 
(a)

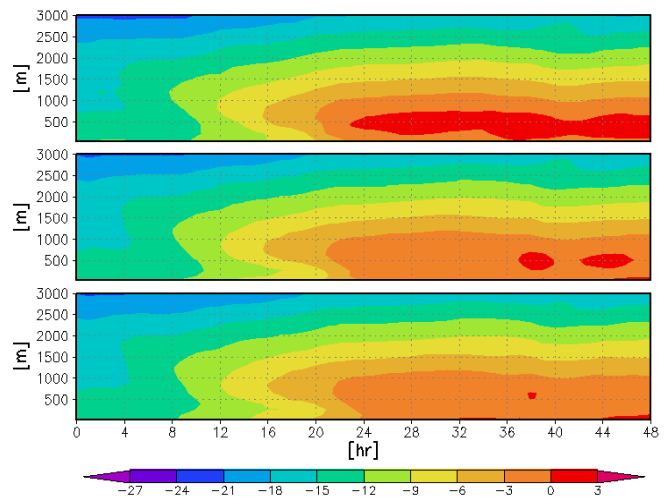

(d)

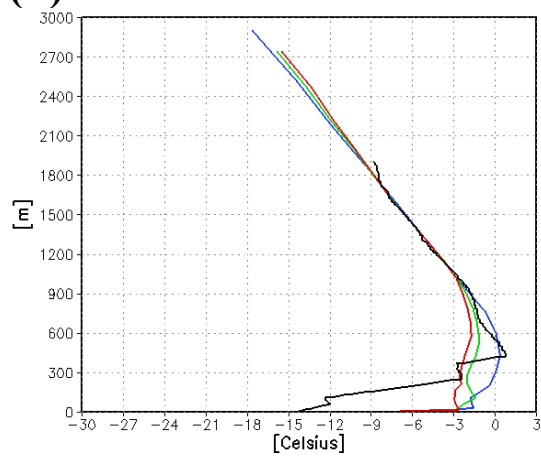

(b)

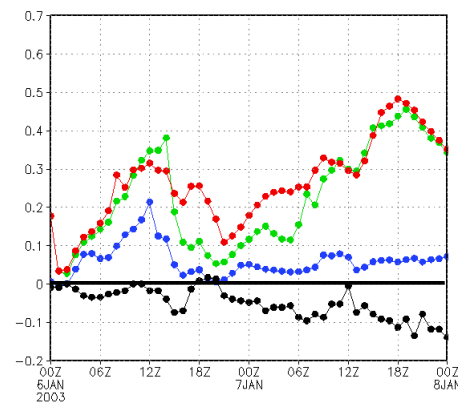

(c)

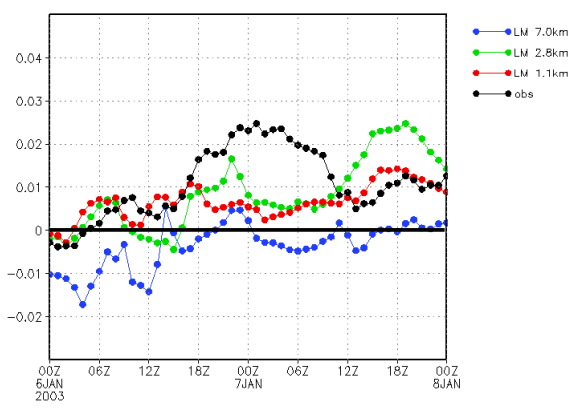

(e)

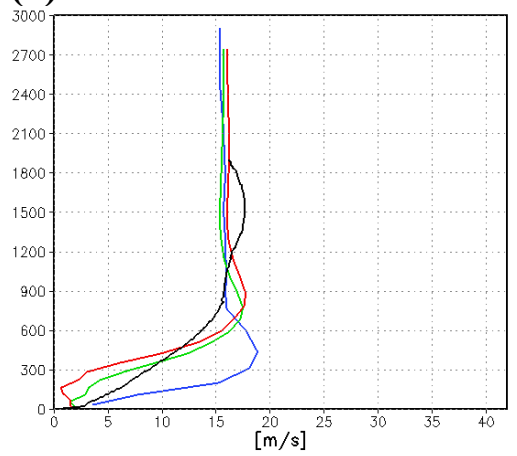

(f)

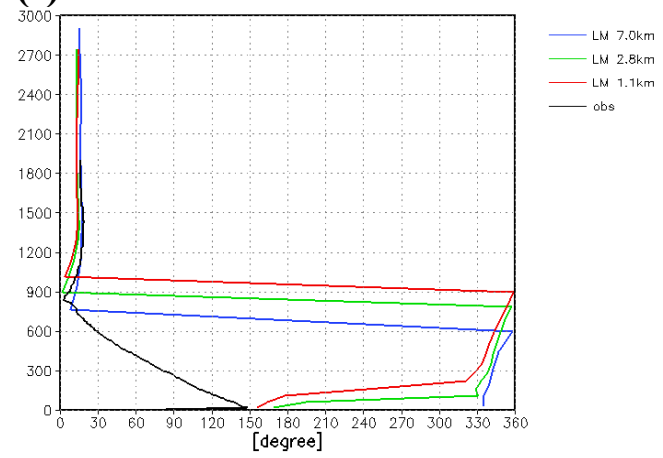

Fig. 11. LM simulations with 7, 2.8 and $1.1 \mathrm{~km}$ resolution on 6 January 2003, (a) Blindern, time series of vertical temperature $\left[{ }^{\circ} \mathrm{C}\right]$, $48 \mathrm{~h}$ forecast starting 00:00 UTC $+00 \mathrm{~h}$. Time series of vertical temperature gradient $\left[{ }^{\circ} \mathrm{C} / \mathrm{m}\right]$ for (b) Hovin and (c) Tryvann/Blindern. Forecasts for 6 January 2003, 00:00 UTC $+24 \mathrm{~h}$, vertical LM profiles and radiosoundings at Blindern for (d) temperature [ $\left.{ }^{\circ} \mathrm{C}\right]$, (e) horizontal wind speed $[\mathrm{m} / \mathrm{s}]$, (f) horizontal wind direction.

very cold nights with strong inversions is underpredicted like for the December 1995 Helsinki episode, and again at least partially caused by features in the dynamic modelling discussed below. For the winter months 2003 in Blindern, statistical scores for the operational $7 \mathrm{~km} \mathrm{LM}$ version are available. They show a negative bias of $2 \mathrm{~m}$ temperature of up to $-3^{\circ} \mathrm{C}$ in winter, but with least underprediction in the early morning hours (Fay et al., 2005). This contrasts sharply with nocturnal overpredictions of above $10^{\circ} \mathrm{C}$ and highlights the uncommon and unusually poor LM performance in temperature forecasting for the January 2003 episode.

The sparse observations of cloudiness for the January 2003 episode indicate overprediction of total cloudiness (a general feature in LM, Schättler and Montani, 2005) especially during the night which would partially explain the overestimated nocturnal minima in contrast to the Helsinki December 1995 episode.

In Fig. 11, forecasts of the vertical temperature profiles and radiosoundings for Blindern for 6 January 2003 are presented. The predictions above the observed inversions (400 to $600 \mathrm{~m}$ ) agree remarkably well with the soundings. In contrast to the Helsinki December 1995 episode, the maximum errors sometimes occur near the ground surface with up to $+9^{\circ} \mathrm{C}$ at night, in other synoptic cases higher up in the inversion layer. Inversions are simulated with all model resolutions but are mostly underpredicted in strength and often elevated instead of ground-based. The forecasts usually deteriorate with increasing LM resolution while in the Helsinki episodes increased model resolution usually leads to at least minor improvement in the simulated inversions. A characteristic pattern emerges when looking at time series of vertical temperature profiles (Fig. 11a). Synoptic warm advection mainly between 300 and $1500 \mathrm{~m}$ starts on 6 January but seems strong enough in layers between about 300 and $900 \mathrm{~m}$ only with the $7 \mathrm{~km}$ LM when compared to radiosounding profiles. For the higher resolutions, therefore, the upper part of the inversion is not enhanced enough by warm advection and remains too cold while the temperatures below about $300 \mathrm{~m}$ are overpredicted. In the lowest model layer below $20 \mathrm{~m}$, temperatures drop rapidly leading to a sharp, non-observed near-surface inversion. A similar behaviour is found during all episode days investigated but there is also one near-perfect inversion forecast for the strong inversion of 7 January 2003 when using the (initialised) analysis of 7 January, 00:00 UTC. 
The temperature inversions are further investigated using vertical temperature gradients available from observations. A near-surface gradient is established using measured temperatures at $8 \mathrm{~m}$ and $25 \mathrm{~m}$ above ground at Valle Hovin station. This is compared to the modelled temperature gradient between the lowest model level above the model orography at Valle Hovin (roughly $34 \mathrm{~m}$ for $7 \mathrm{~km}$ resolution and $20 \mathrm{~m}$ for $2.8 \mathrm{~km}$ and $1.1 \mathrm{~km}$ resolution) and the $2 \mathrm{~m}$ temperature (Fig. 11b). In all cases, inversions are indicated by positive values. The temperature gradient tends to increase with higher vertical resolution for the 2.8 and $1.1 \mathrm{~km}$ simulations. Compared to the measurements at Valle Hovin, the gradient improves with increasing resolution for the November 2001 episode but misses the January 2003 observations which hardly show an inversion for the lowest $25 \mathrm{~m}$.

Another approximate temperature gradient covering the lowest $400 \mathrm{~m}$ of the boundary layer is introduced between the $2 \mathrm{~m}$ temperatures measured at Tryvann hill and Blindern which are only a few kilometres apart although the Tryvann measurements are not identical with free atmosphere conditions. The approximate boundary layer inversion strength between Tryvann and Blindern is underpredicted especially in the strong nocturnal inversion of 6 to 7 January. This may be partly due to the $2 \mathrm{~m}$ temperature at Blindern being overestimated by specific features of the stability-dependent interpolation between surface and the lowest prognostic level in the LM for very stable conditions. The gradient generally improves with increasing horizontal resolution (Fig. 11c). Obviously, the structure especially of strong inversions like those during the January 2003 episode or the Helsinki December 1995 episode is not correctly captured with the LM.

Deficient inversion forecasts may be accompanied (caused or intensified) by deviations of the simulated wind fields as was already shown for the December 1995 Helsinki inversions. The observed persistently low $10 \mathrm{~m}$ wind speeds (of 0 to $2 \mathrm{~m} / \mathrm{s}$ especially for the January episode) at Blindern and Valle Hovin especially in the $1.1 \mathrm{~km} \mathrm{LM}$ are a key cold pool inversion characteristic in the valleys for both episodes. The simulations improve with increasing resolution especially for January 2003 and are well predicted with the $1.1 \mathrm{~km}$ (and $2.8 \mathrm{~km}) \mathrm{LM}$ except at the end of the 3 day period investigated. Time series of LM vertical profiles of wind show an increase in velocities $12-15 \mathrm{~h}$ premature at the valley stations compared with observations leading to premature vertical mixing and the early temperature rise in Fig. 10. The LM profiles show a boundary layer wind regime below 600-900 (1200) $\mathrm{m}$ distinct from the northerly synoptic winds above. Boundary layer wind speed is permanently overpredicted in the $7 \mathrm{~km} \mathrm{LM}$ from noon of 6 January until 9 January leading to exceeding vertical exchange with the warm air aloft. The sharp temperature drop below the inversion top is thus not simulated and the surface temperatures overestimated in the $7 \mathrm{~km} \mathrm{LM}$. The vertical profile of the inversion for the higher resolution simulations, especially in the $1.1 \mathrm{~km}$ version, may be explained with different dependencies in com- parison with radiosoundings at Blindern for 6 January $+24 \mathrm{~h}$ in Figs. 11d-f. Above $400 \mathrm{~m}$ warm advection seems insufficient in combination with overestimated wind speeds leading to a decrease of inversion strength from the inversion top. Below $400 \mathrm{~m}$, the winds are very slight (between 1 and $3 \mathrm{~m} / \mathrm{s}$ for $1.1 \mathrm{~km} \mathrm{LM}$ ) and underpredicted and turn anti-clockwise to southerly/southwesterly directions with increasing resolution and decreasing height. This may be caused by the higher and steeper model topography leading to lower level streamlines being diverted around the hills in the deeper valleys and a mountain blocking effect with subsidence penetrating below $400 \mathrm{~m}$ in LM at the forecast time discussed. The diverted slight southwesterly winds below $400 \mathrm{~m}$ may also lead to warm advection in the air lingering for some hours above Oslo fjord which is ice-free and about $10^{\circ} \mathrm{C}$ warmer than the surroundings at the beginning of the night. This agrees with vertical profiles of potential temperature showing that the stratification always remains stable but often with reduced stability in the lowest $200 \mathrm{~m}$ for the higher resolutions.

Several effects may thus combine to lead to temperature overprediction and reduced stability in the lower boundary layer above Oslo especially in the $1.1 \mathrm{~km}$ version of LM. A similar pattern is encountered during most of the episode and leads to a lifting of the ground-based inversion or even its complete dissolution for the $1.1 \mathrm{~km}$ LM versions whereas in the operational $7 \mathrm{~km}$ version, inversions remain groundbased and retain a larger inversion strength. For the topography height and steepness increasing with LM resolution near to the Oslo stations, the decreasing model skill may partly be due to the terrain-following vertical coordinate system that was shown to deteriorate valley inversions close to mountains in comparison with simulations with a $\mathrm{z}$-coordinate model (Steppeler, 2002).

The November 2001 episode is also influenced by a decisive dynamic feature. The strong surface inversions break down due to intermittent wind peaks related to northwesterly foehn penetrating into the Oslo valley basin (Valkama and Kukkonen, 2004). The low wind speeds, but also the observed occurrence and phase of the narrow wind peak are very well represented with the $1.1 \mathrm{~km} \mathrm{LM}$ (though with underpredicted wind maximum) in Blindern early on 19 November 2001. The LM, however, does not simulate the very sharp Valle Hovin peak late on 19 November 2001 that marks the end of the maximum $\mathrm{NO}_{\mathrm{x}}$ and particle concentrations at all Oslo air quality stations for the whole episode.

In conclusion, the dependencies of meteorological parameters in the Oslo January 2003 episode are highly complex and seem mainly induced by the changes of topography with increasing LM resolution which may lead to large dynamic and thermal differences between the LM versions themselves and in comparison with observations. In the very-high resolution LM, not only mesoscale phenomena like gravity waves, channelling and convergence and divergence lines are better developed because of the improved model orography. This version is also capable of differentiating and simulating 
local effects like mountain blocking and lee subsidence due to small mountains. In the Oslo January 2003 episode, these improved capabilities still lead to deterioration, which may be due to the specific episode conditions like direction and strength of synoptic flow in relation to the high-resolution model topography in windward of Oslo during that episode and the chance of advected air masses traversing Oslo fjord at a time of high temperature contrasts.

Thus, the main characteristic of winter inversion-induced episodes, i.e. sufficient inversion strength, is not modelled well with all LM resolutions but especially the higher ones for the January 2003 episode. On the contrary, the key factor of low wind speed improves with higher LM resolution thus retaining the slight winds in the lower boundary layer for a longer time and showing the sheltering capabilities of the high-resolution LM.

Comparison with longer-term statistics reveal that the January 2003 episode certainly displays extreme meteorological conditions especially concerning inversion strength. The LM during the less meteorologically extreme November 2001 episode thus shows a much improved and satisfactory forecasting performance.

\subsection{LM simulations for Valencia episodes}

In Southern Europe, photochemical episodes occur in larger, partly non-urban areas from spring to autumn, often in combination with higher particle concentrations and in addition to winter traffic-induced particle episodes. These photochemical episodes arise under anticyclonic conditions with low winds and high solar insolation. Recurring diurnal temperature cycles play a leading role especially in ozone formation. Additionally, in topographically complex subtropical latitudes like the Mediterranean basin, the appropriate simulation of the non-local mesoscale circulations is paramount as they govern the distribution of ozone and its precursors (Millán et al., 2002).

The modelling domain for the Valencia/Castellón episode is centered on the Castellón conurbation with a variety of industries and pollutant emissions. The atmospheric dynamics in the area is governed by the sea and the nearby mountains. The numerous river valleys rectangular to the coast channel the sea breeze and coastal air loaded with emissions towards inland areas where it combines with inland orographic upslope winds. Mesoscale, non-local effects like orographic injection, return flows and compensatory coastal subsidence lead to recirculation of pollutants and determine the high ozone levels in the whole circulation region at urban scales but may influence synoptic features as well. The interaction between the different scales must, therefore, be reproduced correctly in the models. In contrast to the winter episodes discussed above, these photochemical episodes are frequent or even chronic and are not characterised by meteorological extremes. A full description of the meteorological and air quality conditions and of simulations is provided in Millán et al. (2002).

In this paper, however, only the key episode factor of mesoscale circulations driving pollutant dispersion will be discussed which are the complex mesoscale wind systems and pollutant recirculation.

For the Valencia area, increasing LM resolution involves distinct changes in topographic height and roughness length. The surface roughness decreases at high mountain stations because part of the subscale effects of roughness are assumed to be explicitly taken account of by the parameterisations in the higher resolution LM. The more detailed topography with higher mountains and deeper valleys increases the complexity of the temperature and wind fields and improves the description of diurnal breeze circulations, nocturnal drainage winds, coastal subsidence, and of convergence and divergence lines, again confirming results for other models (see Mass et al., 2002). In combination with the dynamical and thermal effects due to the changed physiographic parameters, the near-surface fields of temperature, wind speed and direction generally improve with higher LM resolution compared to observations.

The evolution of the characteristic mesoscale circulation is discussed in detail in a time series of vertical cross sections and horizontal fields. The vertical cross section in Fig. 12 cuts from the sea to the first high mountain ridge south of the Ebro delta for the forecast starting 27 September 1999, 00:00 UTC. Nocturnal cooling of the high mountains has led to nocturnal drainage winds observed at 00:00 UTC $+03 \mathrm{~h}$ (05:00 a.m. local time) with boundary layer subsidence in a broad coastal belt (Fig. 12a). At 00:00 UTC $+10 \mathrm{~h}$, a sea breeze circulation has developed confined to $800 \mathrm{~m}$ depth, as well as an upslope orographic wind further inland and uphill (Fig. 12b). Both systems are still separated by a narrow downdraft region possibly enhanced from the mountain gravity wave system aloft. By 00:00 UTC $+13 \mathrm{~h}$, both wind systems have combined (Fig. 12c) and their leading edge reaches far inland and even up to the crest of the main mountain ridge where they act as a separate orographic chimney for the injection of pollutants aloft. These features fully correspond to observations and description of the circulation patterns in Millán et al. (2002). The vertical extent of the circulation has risen to about $1300 \mathrm{~m}$. The upper circulation branch returns to the coast aloft. The compensatory subsidence along the return leads to subsidence inversions which separate the inland surface breeze from the return flows aloft (Fig. 12c). It also stratifies injected pollutants and creates new (ozone) reservoir layers moving towards the sea where they are mixed down and reinjected into the circulation with the sea breeze of the following days. Thus, the high-resolution LM simulates the typical patterns that lead to injection and recirculation of pollutants and to the observed ozone and precursor levels reaching higher values day after day. 
(a)

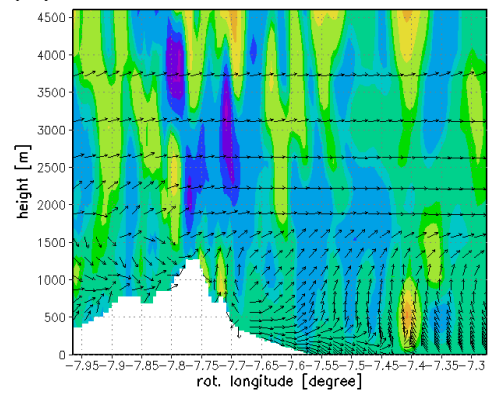

(d)

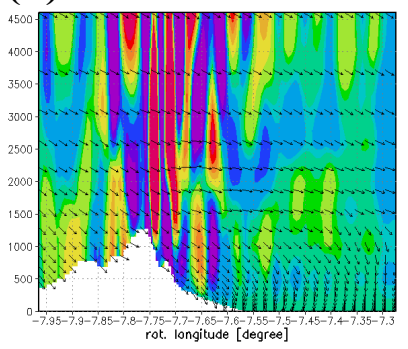

(b)

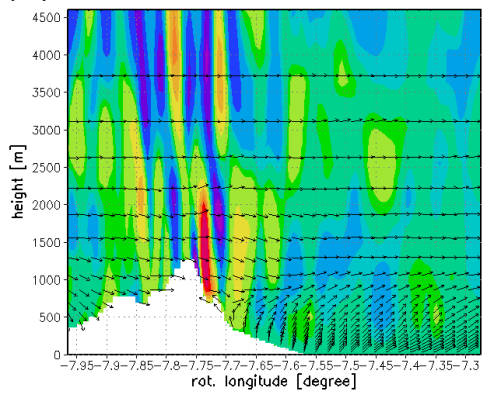

(f)

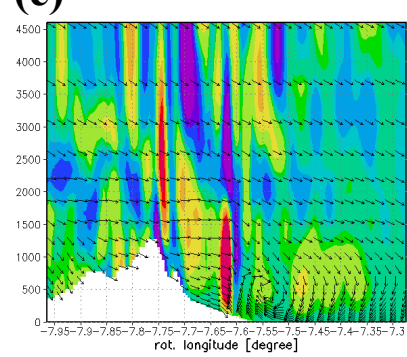

(c)

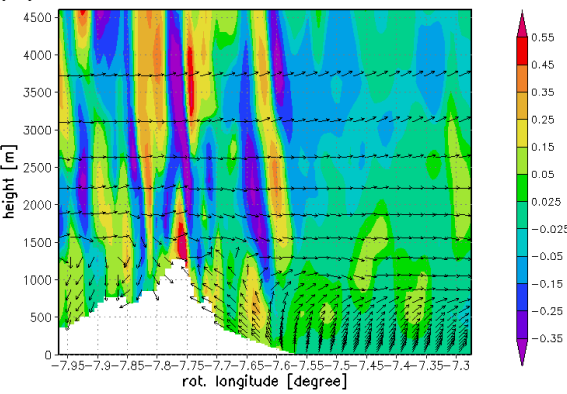

(g)

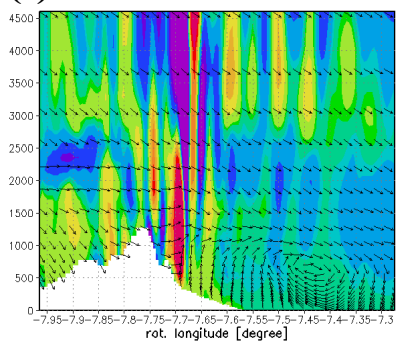

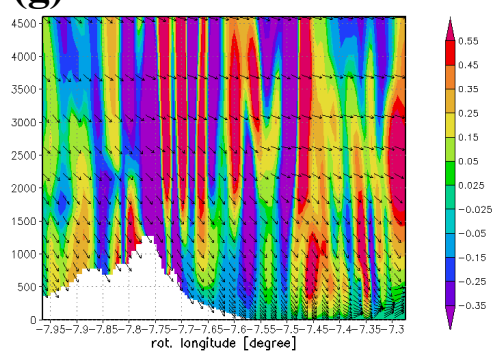

Fig. 12. Vertical cross section prependicular to Mediterranean coast north of Valencia (height [m] vs. LM rotated geographical longitude $\left[{ }^{\circ}\right]$ ) for vertical velocity [m/s] (shaded contours) and horizontal wind vector (arrows) for 1.1 km LM forecasts, (a) 27 September 1999, 00:00 UTC +3 h, (b) 27 September 1999, 00:00 UTC +10 h, (c) 27 September 1999, 00:00 UTC +13 h, (d) 28 September 1999, 00:00 UTC +10 h, (e) 28 September 1999, 00:00 UTC +13 h, (f) 28 September 1999, 00:00 UTC +14 h, (g) 30 September 1999, 00:00 UTC +14 h.

(a)

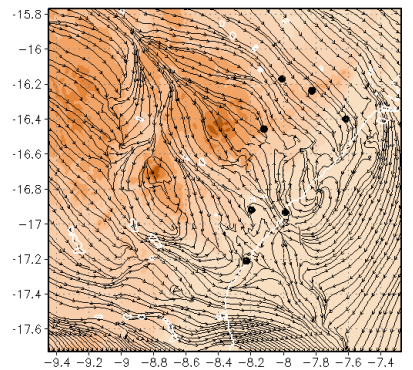

(b)

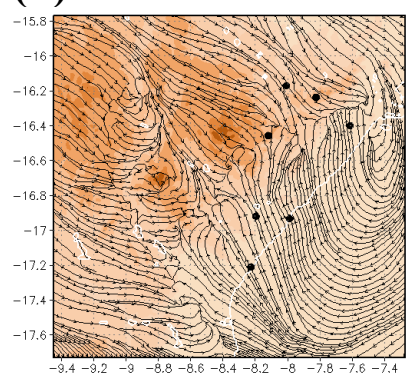

(c)

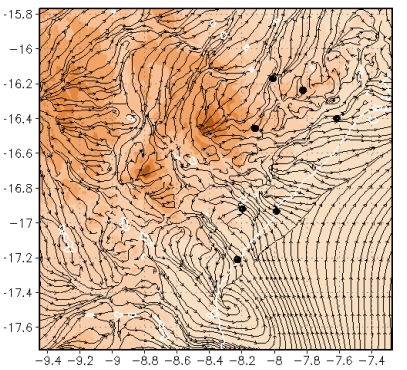

(d)

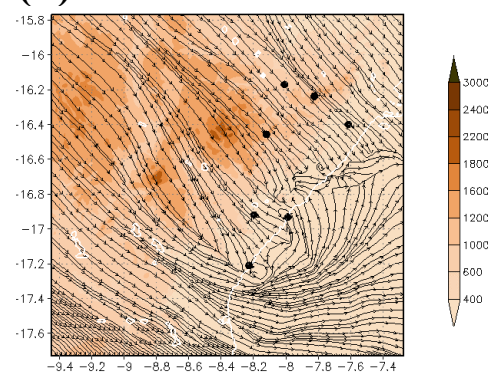

Fig. 13. $1.1 \mathrm{~km}$ LM streamlines of $10 \mathrm{~m}$ wind speed on topographic map of Valencia coastal region with 7 regional observation stations (black dots), coastline in white, axes: LM rotated latitude and longitude [ ${ }^{\circ}$ ]. (a) 28 September 1999, 00:00 UTC $+10 \mathrm{~h}$, (b) 28 September 1999, 00:00 UTC +14 h, (c) 28 September 1999, 00:00 UTC +23 h, (d) 30 September 1999, 00:00 UTC +13 h.

These mesoscale circulations change in shape and strength during the five episode days investigated. During the episode with westerly synoptic flow, mesoscale return flow and synoptic flow reinforce each other. On 28 September e.g., the dominant synoptic scale west winds and strong lee wave pattern in the free atmosphere suppress the sea breeze in the morning (Fig. 12d). A small coastal circulation is formed late at 00:00 UTC $+13 \mathrm{~h}$ showing a closed vertical and also horizontal circulation (Fig. 12e). It grows in size in the afternoon but the leading edge only reaches higher mountains after 14:00 UTC that day (Fig. 12f). The recharging period associated with the periodic sea breeze development in the area is terminated on 30 September 1999 by a cold front passage from the northwest and leads to temporarily decreasing concentrations. Coastal stations may experience a short sea breeze development due to the large Mediterranean insolation and the specific topographic features of this area even under these advective conditions with dominant synoptic forcing. This regional feature is also simulated with LM (Figs. 12g, 13d).

Figures $13 a-b$ show the period of merging in a time series of horizontal wind fields in the northeastern part of the 
highest resolution model domain. On 28 September, the circulation development is delayed. At 00:00 UTC $+10 \mathrm{~h}$ (Fig. 13a) a mixture of drainage winds and starting sea breeze is encountered along the coast, while upslope winds are modelled on the inland mountain ridge. Four hours later, the sea breeze is fully developed and merged with the upslope winds into a combined breeze (Fig. 13b). During the night, thermal circulations die down, areas of subsidence appear above the mountain tops and cold surface air masses flow downslope along the valleys accelerated by gravity with convergence lines along the axis of many valleys. An additional important mesoscale feature on this Mediterranean coast is the convergence line along the coast, resulting from the temperature gradient between the warmer air mass above sea and the cooler drainage air masses. The sea air mass acts as a convective barrier delaying and turning the drainage flows parallel to the coastline out at sea (Fig. 13c). Drainage flows and convergence influence the amount of aged pollutants which will re-enter inland with the sea breeze the next morning and contribute to pollution levels (Millán et al., 2002).

No vertical soundings or sea observations are available to validate the vertical development and extent of these simulated circulations. Yet the very high-resolution LM simulates all the qualitative patterns and even detail connected with the key episode factor of mesoscale circulations which are observed and investigated for the mountainous Iberian coasts.

\section{Conclusions and outlook}

The operational LM with $7 \mathrm{~km}$ horizontal resolution and 35 vertical layers was downscaled to $2.8 \mathrm{~km}$ and $1.1 \mathrm{~km}$ and 45 layers resolution by one-way interactive nesting while retaining the operational non-urbanised parameterisations. Episode simulations show that forecasts often improve due to higher resolution especially in mountainous areas like Oslo and Valencia where features depending on topography like temperature, wind speeds, channelling, convergence/divergence lines and mesoscale circulations are better described. Evaluation against station observations also indicates small forecast gains due to the improved land fraction, soil type or roughness length at coastal grid points especially for the Helsinki episodes (Neunhäuserer and Fay, 2004). Only for the extreme Oslo January 2003 episode, the vertical structure of the observed temperature inversion deteriorates with increasing resolution due to erroneous temperature advection and mountain-induced effects while at the same time simulating but overpredicting the mountain sheltering of the Oslo cold air pool.

The dominating meteorological features in the winter inversion-induced and suspended dust episodes in the northern cities of Helsinki and Oslo are ground-based temperature inversions and low wind speed that lead to stagnant air and very high pollution levels. The simulation of surface temperatures under inversion conditions and of total inversion strength at the inversion level may cause problems in LM. This is especially true for the extreme Helsinki December 1995 episode and the strong inversions in Oslo in January 2003. In both episodes the LM also exhibits a very large bias in comparison with the evaluated one-year statistical scores of the LM. There is some improvement with higher horizontal and vertical resolution in Helsinki but also deterioration in Oslo because various dynamic or thermal parameters may combine in a detrimental fashion. However, inversion forecasts are much improved for the other episodes. Wintertime inversion problems are currently encountered with the $7 \mathrm{~km} \mathrm{LM}$ version in the operational central European domain in rural areas as well. They confirm that nocturnal stable air presents the greatest difficulty for episode simulations in urban areas but poses a large problem in general simulations and for other models as well (Piringer and Kukkonen, 2002; Berge et al., 2002; Rantamäki et al., 2005; Fay et al., 2005). The explanations for this model deficiency may vary between the episodes depending on specific coastal location and physiographic parameters, topography, season and synoptic situation. They are found or suspected in the parameterisations of the surface layer and the soil scheme. The extreme Helsinki (and partly the Oslo) episode apparently suffers from insufficient model stability which leads to overestimation of transfer and diffusion coefficients causing overprediction of vertical exchange and possibly also explaining overestimated inversion height and underestimated inversion strength. For extreme inversions, T2m may also be overestimated by specific features of the stability-dependent interpolation between surface and lowest prognostic level (Neunhäuserer et al., 2004). The model assumption of invariable snow characteristics in the LM soil scheme may also influence surface fluxes and the development of shallow inversions but is improved in the current operational LM. Dynamic factors play an important role when wind speed and vertical exchange are overestimated. In combination with errors in wind direction and large temperature gradients like those between the unfrozen sea (in reality and/or in the model) and the very cold land masses in Scandinavian winters, erroneous temperature advection (warm advection) is encountered, inversion strengths are reduced and surface temperatures overestimated. These effects were investigated in detail for the most extreme Helsinki December 1995 and the Oslo January 2003 episodes. Depending on the synoptic and topographic conditions, these effects may be highly nonlinear and part of positive feedback mechanisms where small changes in model parameters, or simulated deviations from observations, lead to large changes in meteorological parameters and thus in model forecast skill. Similar effects are reported for the Helsinki December 1995 episode in Rantamäki et al. (2005). A mountain sheltering effect is described but even overpredicted with the $1.1 \mathrm{~km}$ LM version.

The LM shows much better performance in the less extreme Helsinki and Oslo suspended dust episodes, and forecasts generally improve with increasing model resolution. 
Especially in the Oslo November 2001 episode, forecasts of near-surface temperatures and slight wind speeds show good skill even in inversion conditions (with no soundings available to validate vertical profiles). In the Helsinki spring dust episodes, LM skill for all near-surface parameters is much improved including the development of distinct diurnal cycles of temperature, relative humidity and surface energy fluxes. This applies although boundary layer temperatures are usually underestimated and humidity overestimated. This is a known LM feature in spring because of the trend to premature thaw, overpredicted soil moisture in the upper soil layer and latent heat flux. Frequently overpredicted nocturnal inversion surface temperatures and generally underestimated inversion strength together with the shape of vertical profiles of wind speed again point towards underpredicted stability and exceeding vertical exchange in those very stable spring nights which still show very strong stability comparable to the December 1995 episode (Table 2).

A very different picture is encountered for the summer photochemical episode in Valencia. The typical meteorological conditions for these episodes occur very frequently on the Mediterranean coast. The dominating factor for forecasting these episodes is the development of the mesoscale circulation systems in the coastal mountain area. The LM succeeds well in forecasting the overall development, daily variations and even detailed features of these recirculations as observed or simulated elsewhere and fully described in Millán et al. (2002). Certainly deviations are encountered on the local scale and in comparison with measurements but the complex circulation is adequately simulated.

In conclusion, the LM is well set to provide meteorological forecasts as input to urban air quality models for varying types of episodes in different seasons of the year and European climate zones even at the fringe of its operational domain. Only extreme episode conditions pose performance problems, and for both Northern European episodes investigated they are connected to insufficient predictions of stability and inversion strengths. Even for other less extreme episodes in Helsinki but in the Po valley as well (Fay et al., 2005) these conditions show the poorest forecast performance in agreement with general LM and NWP experience even for rural areas. Therefore, it is paramount to improve forecasting of very stable conditions in NWP models in general in order to reach better urban meteorology forecasting for inversion-induced episodes as well. Under the adverse circumstances of strong inversions, the urbanisation of NWP models will hardly achieve improvements or be even counterproductive. As a first step, the operational LM surface transfer scheme will be improved for stable stratification in order to forecast better near-surface temperatures under model inversions. The future LM shall contain a vertically resolved roughness layer with the lowest levels at $2 \mathrm{~m}$ and $10 \mathrm{~m}$ in an advanced generalised boundary layer parameterisation.

In many less extreme episodes, improvements are achieved by increasing LM horizontal resolution from $7 \mathrm{~km}$ to $2.8 \mathrm{~km}$ and $1.1 \mathrm{~km}$ and the number of horizontal layers from 35 to 45 , also in comparison with urban point measurements. This is true although the LM version used contains no urbanised physiographic parameters or parameterisations, and the latter are not adapted to the higher scale at all. First urbanisation steps were introduced into the LM by introducing urbanised physiographic parameters and an anthropogenic heat source like in similar model investigations quoted in the introduction. Results for the Helsinki April 2002 episode (Neunhäuserer and Fay, 2005; Neunhäuserer et al., $2006^{1}$ ) show that even simple urbanisation measures do improve the LM performance compared to measurements at urban stations and introduce urban characteristics, e.g. increased heat storage and Bowen ratio and an urban heat island effect and their appropriate influence on boundary layer height and dispersion calculations. The LM surface parameterisation under development is planned as an advanced and physically consistent generalised high-resolution boundary layer parameterisation scheme that is also suitable for the urban canopy and roughness layer, while the urban canopy layer parameterisation by Martilli et al. (2002) has recently been included into the Swiss LM version aLMo during the FUMAPEX project.

Acknowledgements. This study is part of the EU FP5 project FUMAPEX (Integrated Systems for Forecasting Urban Meteorology, Air Pollution and Population Exposure), EVK4-CT2002-00097, 2002-2005, WP3 (Testing the quality of different operational meteorological forecasting systems for urban areas), funded by the European Union. The authors thank their DWD colleagues in NWP modelling, M. Raschendorfer, J.-P. Schulz, D. Majewski, E. Heise, U. Damrath, U. Schättler, T. Hanisch, J. Förstner, M. Baldauf, C. Schraff and M. Buchhold for valuable discussions and support.

Edited by: A. Baklanov

\section{References}

Baklanov, A.: Possible improvements in the DMI-HIRLAM for parameterisations of long-lived stably stratified boundary layer, DMI Internal Report, No. 00-15, 15 pp, 2000.

Baklanov, A., Rasmussen, A., Fay, B., Berge, E., and Finardi, S.: Potential and shortcomings of numerical weather prediction models in providing meteorological data for urban air pollution forecasting, Water, Air, Soil Pollut.: Focus, 2(5-6), 43-60, 2002.

Baklanov, A. (Ed.): FUMAPEX final scientific report. 3 vols., DMI Copenhagen, December 2005, http://fumapex.dmi.dk/Pub/ Docu/Reports/FUMAPEX-FSR-vol1.fv.pdf, ...-vol2.fv.pdf, ...vol3.fv.pdf, 2005.

Baklanov, A., Mestayer, P., Clappier, A., Zilitinkevich, S., Joffre, S., Mahura, A., and Nielsen, N. W.: On the parameterisation of the

\footnotetext{
${ }^{1}$ Neunhäuserer, L., Fay, B., and Raschendorfer, M.: Towards urbanisation of the non-hydrostatic numerical weather prediction model Lokalmodell (LM), Bound. Layer Meteorol., under review, 2006.
} 
urban atmospheric sublayer in meteorological models, Atmos. Chem. Phys. Discuss., 5, 12 119-12 176, 2005a.

Baklanov, A., Mahura, A., Nielsen, N. W., and Petersen, C.: Approaches for urbanization of DMI-HIRLAM NWP model, HIRLAM Newsletter, 49, 61-75, 2005b.

Berge, E., Karppinen, A., Kukkonen, J., Køltzow, M. Ø., and Slørdal, L. H.: Simulations of wintertime inversions in northern European cities by use of NWP-models, in: Proceedings of the COST 715 Expert Meeting "Mixing height and inversions in urban areas", edited by: Piringer, M. and Kukkonen, J., Toulouse, France, 3-4 October 2001, European Commission, Brussels, 75$88,2002$.

Bergeron, G., Laprise, R., and Caya, D.: Formulation du modèle de mésoéchelle compressible communautaire (MC2), Centre coopératif pour la recherche en mésométéorologie (CCRM), 165 pp, 1994.

Cope, M. E., Hess, G. D., Lee, S., Tory, K., Azzi, M., Carras, J., Lilley, W., Manins, P. C., Nelson, P., Ng, L., Puri, K., Wong, N., Walsh, S., and Young, M.: The Australian air quality forecasting system. Part 1: Project description and early outcomes, J. Appl. Meteorol., 43, 649-662, 2004.

Davies, H. C.: A lateral boundary formulation for multi-level prediction models, Quart. J. Roy. Meteorol. Soc., 102, 405-418, 1976.

Drusch, M.: Sea ice analyses for the Baltic Sea, ECMWF Newsletter, 103, 6-11, 2005.

Dudhia, J.: A nonhydrostatic version of the Penn State-NCAR Mesoscale Model: Validation tests and simulations of an Atlantic cycleone and cold front, Mon. Wea. Rev., 121, 1493-1513, 1993.

Dupont, S., Otte, T. L., and Ching, J. K. S.: Simulation of meteorological fields within and above urban and rural canopies with a mesoscale model (MM5), Bound. Lay. Meteorol., 113, 111-158, 2004.

Fay, B., Schrodin, R., Jacobsen, I., and Engelbart, D.: Validation of mixing heights derived from the operational NWP models at the German Weather Service, in: The determination of the mixing height - current progress and problems, EURASAP workshop proceedings, Risoe Nat. Lab, Denmark, 55-58, 1997.

Fay, B., Neunhäuserer, L., Pérez-Landa, G., Palau, J. L., Dieguez, J. J., Ødegaard, V., Bjergene, N., Sofiev, M., Rantamäki, M., Valkama, I., Kukkonen, J., Rasmussen, A., and Baklanov, A.: Model simulations and preliminary analysis for three air pollution episodes in Helsinki, Deliverable 3.3 of the EU FP5 FUMAPEX project, Offenbach, Germany, 66 pp, 2004.

Fay, B., Neunhäuserer, L., Palau, J. L., Pérez-Landa, G., Dieguez, J. J., Ødegaard, V., Bonafé, G., Jongen, S., Rasmussen, A., Amstrup, B., Baklanov, A., and Damrath, U.: Evaluation and intercomparison of operational mesoscale models for FUMAPEX target cities, Deliverable 3.4 of the EU FP5 FUMAPEX project, Offenbach, Germany, 110 pp, 2005.

Fisher, B., Kukkonen, J., Piringer, M., Rotach, M. W., and Schatzmann, M.: Meteorology applied to urban air pollution problems: concepts from COST715, Atmos. Chem. Phys., 6, 555564, 2006, mboxhttp://www.atmos-chem-phys.net/6/555/2006/.

Klaic, Z. B. and Nitis, T.: Application of mesoscale model (MEMO) to the greater Zagreb area during summertime anticyclonic weather conditions, Geofizika, 18-19, 31-42, 2001.

Kotroni, V. and Lagouvardos, K.: Evaluation of MM5 Highresolution real-time forecasts over the urban area of Athens,
Greece, J. Appl. Meteorol., 43, 1666-1678, 2004.

Kukkonen, J., Pohjola, M., Sokhi, S., Luhana, L., Kitwiroon, N., Fragkou, L., Rantamäki, M., Berge, E., Ødegaard, V., Slørdal, L. H., Denby, B., and Finardi, S.: Analysis and evaluation of selected local-scale $\mathrm{PM}_{10}$ air pollution episodes in four European cities: Helsinki, London, Milan and Oslo, Atmos. Environ., 39(15), 2759-2773, 2005.

Majewski, D., Liermann, D., Prohl, P., Ritter, B., Buchhold, M., Hanisch, T., Paul, G., Wergen, W., and Baumgardner, J.: The operational global icosahedral-hexagonal grid point model GME: Description and high resolution tests, Mon. Wea. Rev., 130, 319338, 2002.

Martilli, A., Clappier, A., and Rotach, M. W.: An urban surface exchange parameterisation for mesoscale models, Bound. Layer Meteorol., 94, 357-397, 2002.

Mass, C. F., Owens, D., Westrick, K., and Colle, B. A.: Does increasing horizontal resolution produce more sillful forecasts?, Bull. Amer. Meteorol. Soc., 83, 407-430, 2002.

Mellor, G. L. and Yamada, T.: A hierarchy of turbulence closure models for planetary boundary layers, J. Atmos. Sci. 31, 17911806, 1974.

Millán, M. M. (Ed.): Ozone dynamics in the Mediteranean basin, Air Poll. Res. Report 78, Coll. of scient. papers resulting from the MECAPIP, RECAPMA and SECAP Projects, European Commision and CEAM, Valencia, Spain, 287 pp, 2002.

Moussiopoulos, N.: The EUMAC Zooming Model, a tool for localto-regional air quality studies, Meteorol. Atmos. Phys., 57, 115133, 1995.

Neunhäuserer, L. and Fay, B.: Impact of grid refinement on operational LM modelling results for selected Helsinki episodes, Proceedings of LM-user seminar 2004, March 2004, Langen, Germany, 2004.

Neunhäuserer, L., Fay, B., Baklanov, A., Bjergene, N., Kukkonen, J., Ødegaard, V., Palau, J. L., Pérez-Landa, G., Rantamäki, M., Rasmussen, A., and Valkama, I.: Evaluation and comparison of operational NWP and mesoscale meteorological models for forecasting urban air pollution episodes - Helsinki case study, in: Proceedings of the 9th Int. Conference on Harmonisation within Atmospheric Dispersion Modelling for Regulatory Purposes, edited by: Suppan, P., Garmisch-Partenkirchen, Germany, 1-4 June 2004, Forschungszentrum Karlsruhe GmbH, Karlsruhe, 245-249, 2004.

Neunhäuserer, L. and Fay, B.: Towards predicting urban air pollution episodes: Introduction of urbanised parameters into the mesoscale Lokalmodell (LM) of the German Weather Service, in: Proceedings of the 5th International Conference on Urban Air Quality, edited by: Sokhi, R. S., Millán, M. M., and Moussiopoulos, N., Valencia, Spain, 29-31 March 2005.

Piringer, M. and Kukkonen, J. (Eds): Mixing height and inversion in urban areas, Proceedings of Workshops 3 and 4 October 2001, Toulouse, France, COST Action 715, EUR 20451, Europ. Commission, Brussels, 113 pp, 2002.

Piringer, M. and Joffre, S. (Eds): The urban surface energy budget and mixing height in European cities: Data, models and challenges for urban meteorology and air quality, Final Report of WG2 COST Action 715. 194 pp, 2005.

Pohjola, M. A., Rantamäki, M., Kukkonen, J., Karppinen, A., and Berge, E.: Meteorological evaluation of a severe air pollution episode in Helsinki on 27-29 December 1995, Boreal Environ. 
Res., 9, 75-87, 2004.

Rantamäki, M., Pohjola, M., Kukkonen, J., Bremer, P., and Karppinen, A.: Evaluation of two versions of the HIRLAM model against meteorological data during an air pollution episode in Southern Finland, 27-29 December 1995, Atmos. Environ., 39, 2775-2786, 2005.

Schättler, U. and Montani, A. (Eds.): COSMO Newsletter No.5, 2005.

Skouloudis, A. N. and Suppan, P.: Methodology for the urbanimpact assessment modelling in the frame of AUTO-OIL II, EUR Report no. EUR19556 EN/2000, 2000.

Sokhi, R. S., Luhana, L., Kukkonen, J., Berge, E., Slørdal, L. H., and Finardi, S.: Analysis and Evaluation of Air Pollution Episodes in European Cities, in: Proceedings of the COST 715 Expert Meeting "Mixing height and inversions in urban areas", edited by: Piringer, M. and Kukkonen, J., Toulouse, France, 3-4 October 2001, Europ. Commission., Brussels, 65-74, 2002.
Steppeler, J., Bitzer, H. W., Minotte, M., and Bonaventura, L.: Nonhydrostatic Atmospheric Modeling using a z-Coordinate Representation, Mon. Wea. Rev., 130(8), 2143-2149, 2002.

Steppeler, J., Doms, G., Schättler, U., Bitzer, H. W., Gassmann, A., Damrath, U., and Gregoric, G.: Meso-gamma scale forecasts using the nonhydrostatic model LM, Meteorol. Atmos. Phys., 82(1-4), 75-96, 2003.

Toll, I. and Baldasano, J. M.: Photochemical modelling of the Barcelona area with highly disaggregated anthropogenic and biogenic emissions, Atmos. Environ., 34(19), 3069-3084, 2000.

Valkama, I. and Kukkonen, J. (Eds): Identification and classification of air pollution episodes in terms of pollutants, concentration levels and meteorological conditions, Deliverable 2.1 of the EU 5FP FUMAPEX project, Helsinki, 30 pp, 2004.

Zilitinkevich, S. S., Baklanov, A., Rost, J., Smedman, A.-S., Lykosov, V., and Calanca, P.: Diagnostic and Prognostic Equations for the Depth of the Stably Stratified Ekman Boundary Layer, Quart. J. Roy. Meteorol. Soc., 128, 25-46, 2002. 